\title{
Missions and Heterogeneous Social Change: Evidence from Border Discontinuities in the Emirates of Nigeria ${ }^{1}$
}

\author{
Dozie Okoye \\ Dalhousie University \\ Roland Pongou \\ University of Ottawa
}

October 20, 2021

\footnotetext{
${ }^{1}$ This is a substantially revised version of a paper previously circulated as "Historical Missionary Activity, Schooling, and the Reversal of Fortunes: Evidence from Nigeria". We wish to thank Daron Acemoglu, Kehinde Ajayi, David Autor, Bastian Becker, Moussa Blimpo, Esther Dufflo, Marcel Fafchamps, Talan Iscan, Remi Jedwab, David S. Jacks, Marie Christelle Mabeu, Lars Osberg, Peter Temin, Leonard Wantchekon, and Tite Yokossi for insightful comments and discussions during the course of this project. Our gratitude goes to participants at the 2021 LEAP Lecture, the 2021 SASE Conference, the AEA meetings, the Canadian Network for Economic History conference, and the Dalhousie University Macroeconomic and Development Group for useful comments. We are responsible for all errors. Address correspondence to: cokoye@dal.ca or roland.pongou@uottawa.ca.
} 


\begin{abstract}
How and why have colonial-era Christian missions brought about social change in the long run? This paper addresses this question by causally estimating average and heterogeneous effects of colonial-era Christian missions on schooling, fertility, and household wealth in Nigeria. Our identification strategy exploits discontinuities in mission stations around the borders of the Emirates of Northern Nigeria, where missionary activities were restricted by the colonial administration. We find that areas with greater historical missionary activities have higher levels of schooling, lower levels of fertility, and higher household wealth today. Consistent with the predictions of a simple model, the long-run effect of missions on current schooling is not found in areas with early access to government schools, and is larger for population subgroups-women and Muslims-that have historically suffered disadvantages in access to education. Importantly, we show that the restriction of missions from the Emirates of Northern Nigeria has led to a reversal of fortunes, wherein areas that were more prosperous and institutionally developed in the past are relatively poorer today.
\end{abstract}

JEL Classification: I20, N30, N37, N47, O15, Z12.

Keywords: Christian Missions, Restrictions, Education, Fertility, Wealth, Reversal of Fortunes, Heterogeneity, Emirates of Northern Nigeria, Indirect Rule, Africa. 


\section{Introduction}

A number of recent studies document the importance of colonial-era Christian missionary activities for human capital accumulation in a variety of settings, and suggest that significant social and economic changes have been brought about as a result of these missions. However, the extant literature on the impacts of missions is still far from firmly establishing this claim for several reasons. First, this literature has only examined a limited set of outcomes, yielding limited knowledge on the real scope of missionary impacts. Second, this literature has primarily focused on average long-term effects (Michalopoulos and Papaioannou, 2020), which limits our understanding of conditions under which missionary activities have positively influenced human capital accumulation and economic development. Examining heterogeneity in the long-term impacts of historical missionary activities is pertinent given the diversity of cultural, political, and geographic contexts in which these activities occurred. Third, the extant literature does not show that historical missionary activities have altered relative pre-colonial outcomes, which is important for understanding institutional change in colonial Africa (Acemoglu et al., 2002a). In addition to these pending questions, an important obstacle to identifying the causal impacts of missions is the fact that mission stations might have been strategically located, leading to possible endogeneity issues.

In this paper, we study the average and heterogeneous long-term effects of historical Christian missionary activities on human capital accumulation, wealth, and fertility outcomes, and we establish that these activities have led to a reversal of fortunes wherein areas that were more prosperous and institutionally developed in the past are relatively poorer today. To establish causality, we exploit a quasi-natural experimental setting induced by restrictions on Christian missionary activities in some Islamic Emirates of British Northern Nigeria. Using a fuzzy regression discontinuity design framework around the boundaries of the restricted areas, we find that individuals residing in the restricted areas have significantly lower levels of education and wealth and higher fertility compared to their counterparts residing just outside of these areas. In addition, we find that the current situation represents a significant reversal of fortunes, given that the restricted areas were more institutionally developed in the past. Consistent with a simple model of how schooling infrastructure affects schooling demand, we find that the long-term effect of historical missionary activities on schooling is not found in areas with early access to government schools, and is significantly larger for females and Muslims, which are subgroups that have historically suffered disadvantages in access to education in Nigeria (Csapo, 1981).

The arrival of Christian missionaries in Africa was an important historical episode with longstanding impacts on African religions and cultural practices (Sundkler and Steed, 2000; Nunn, 2010; Okoye, 2021). Missionary societies were vital to nineteenth century efforts to end the transatlantic slave trade, and were driven by the firm belief this would be achieved through the introduction of Western education, and Christianity, as a means to advance civilization (Buxton, 1840). Nigeria presents an interesting setting for our analyses because of the rich variation in missionary activity generated by the timing of the British colonial government's policy restricting missionary activity in many areas of the country. As the most populous country in Africa, the area now known as Nigeria attracted several Protestant and Catholic missionaries whose primary method for proselytizing was the school. By the early 1900's, however, Nigeria had become an official British colony, and government administrators who wished to govern through traditional rulers (indirect rule) actively discouraged missionaries from expanding into many areas of Northern Nigeria in favour of political 
stability. ${ }^{1}$ The colonial administration took on the responsibility of providing education in these areas where missions could not operate. ${ }^{2}$ This policy generated large early differences in schooling infrastructure, and attainment, between different areas of Nigeria. As early as 1914, there were already 65,000 primary school pupils in the South, but just 2,100 primary school pupils in the North where the colonial government had taken primary responsibility for schooling and restricted missionary activities (Csapo, 1981).

To examine the long-term effects of early missionary activity in modern Nigeria, we construct a new dataset on the location of primary mission stations and other colonial investments, as at 1928, which we combine with 4 waves of the Nigeria Demographic and Health Surveys. As a baseline, we use country-wide variation in historical missionary activity to find that individuals living in an area within $20 \mathrm{~km}$ of a mission station have over 2 more years of education relative to individuals living in areas located more than $80 \mathrm{~km}$ of a mission station. This estimate decreases to $1.3,0.8$ and 0.7 more years of education for individuals living in areas within $20-40 \mathrm{~km}, 40-60 \mathrm{~km}, 60-80 \mathrm{~km}$ of a mission station, respectively. These estimates control for region fixed effects, distance to the sea, and other factors outlined in Jedwab et al. (2018a) that drive mission locations. ${ }^{3}$ Hence, the estimated effects of historical missionary activity is quite robust to a number of possible confounders.

Nevertheless, one may still find that our large set of control variables do not fully address the endogeneity of mission locations to future development potential. To address this issue, we exploit the aforementioned quasi-natural experiment generated by the historical restrictions placed on Christian missionary activities in the Islamic Emirates of Northern Nigeria. This strategy deals with any concerns about missions strategically locating themselves in better areas, or areas that would have been more successful in the future. We first demonstrate that areas just within and outside the restricted locations are identical in almost every respect, including all other investments by the colonial administration (see Figure 4). However, areas outside the restricted zones are $40 \%$ more likely to have a mission station in 1928 (see Figure 3 and A2). We use a fuzzy regression discontinuity design (RDD) framework to show that individuals living in the restricted areas have about 3 more years of schooling compared to individuals living just outside of the restricted areas. This result holds for areas within $10 \mathrm{~km}$ of the border of restricted areas, and continues to hold when the bandwidth is expanded to include areas within $20 \mathrm{~km}$ or $30 \mathrm{~km}$ of the the restricted areas.

We now turn to the long-term effect of historical missionary activity on fertility behavior. Fertility behavior is related to education and declines with economic development during the demographic transition (Galor and Weil (1999), Galor and Weil (2000)). Our analysis also sheds light

\footnotetext{
${ }^{1}$ See border of restricted areas in Figure 1.

${ }^{2}$ In the section on the historical background, we provide more detailed discussions of the policy, emphasizing that the restrictions on missionary activities neither arose from missionaries nor traditional rulers. We also emphasize that indirect rule was applied across the country and not only in areas where missions were restricted (Afigbo, 1972).

${ }^{3}$ These factors include geographic factors (presence of a major river, total land area, malaria ecology, distance to the nearest border, soil suitability for primary export crops such as cocoa, cotton, groundnuts, and palm oil); colonial investments (presence of the railway line, presence of a major motorway, presence of a hospital, city presence in 1900, presence of a major seaport, township presence in 1928, and presence of a government school in 1928); historical population conditions (total population, population density, and urbanization rate, all measured in the year 1900); and ethnic heritage (presence of an ethnic majority in the local area, and measures for the intensity of agriculture, settlement patterns, political hierarchy, centralization, class stratification, marital living composition, female bias in agriculture, and bride price payments) for the majority historical ethnic group in the local area.
} 
on a key mechanism through which a regime of low human capital and high fertility can persist as a result of a historical shock. Both our baseline estimates and the fuzzy RDD analysis show that historical missionary activity has a negative effect on fertility levels. In our most conservative baseline specification, women living in an area within $20 \mathrm{~km}$ of a mission station have over 0.4 fewer children relative to women living in areas located more than $80 \mathrm{~km}$ away from a mission station, which is 14 percent of the mean total number of children. This estimate decreases to .28, and .2 , fewer children for women living in areas within $20-40 \mathrm{~km}$, and $40-60 \mathrm{~km}$, of a mission station, respectively. We also find that historical missionary activity negatively affects the ideal number of children, implying significant effects on fertility preferences. The results suggest that the significant regional variations in fertility outcomes observed within African countries can be explained by historical missionary activities. This is significant in light of the fact that there is very little research about the effects of historical institutions on fertility behavior in Africa. ${ }^{4}$

A central part of our study is the analysis of heterogeneity in the long-term effects of historical missionary activities in Nigeria. An appeal of this exercise is that it allows us to establish that the supply of, rather than demand for, schooling is the main explanation for the long-term effects of missions on this outcome. It is intended to shed some light into possible mechanisms through which missionary activity has had sustained impacts. This analysis is based on a simple model of how investment in schooling infrastructure affects schooling demand. A key implication of this model is that the long-term effect of missionary activity on contemporary schooling demand should be greater for groups that historically suffered disadvantages in access to education.

Consistent with the model, we find significant impact heterogeneity of missions by gender, religion, and historical access to government schools. First, we find that the long-run effect of missionary activities on schooling is significantly more important for women than for men. This result validates our model's prediction that increased education infrastructure has a larger effect on individuals facing discrimination in the labor market. ${ }^{5}$ Second, we find that the positive effect of missionary activity on schooling is larger for Muslims, another group that historically had limited access to formal education (Dev et al., 2016). It follows that the effect of missions on schooling is not primarily a result of religion and demand for schooling. Consistent with the model, the point estimates reveal that the effect of missionary activity on schooling is stronger among Muslims, because of the lower average levels of schooling infrastructure in Muslim areas.

Third, we analyze how the effects of missionary activities vary by initial conditions that might have driven the demand for, and supply of, education. We find that the long-run effect of missionary activity is substantially smaller, and indistinguishable from zero, in areas that had government schools in 1928 (same time as the missions in our data). This finding implies that government schools were a substitute for missionary schools, and establishes that the supply of, rather than demand for, school infrastructure is a key mechanism driving the long-term effect of missionary

\footnotetext{
${ }^{4}$ A notable exception is Canning et al. (2021) who show that differences in colonial population policies explain differences in fertility behavior between the former British and French colonies of Africa.

${ }^{5} \mathrm{An}$ increase in schooling infrastructure from missionary activities in an area lowers the marginal cost of education, and encourages relatively more female education. A preference for male education in the early missionary period as a result of economic realities is supported by some historical evidence; for example, the Chiefs of Bonny, in Southern Nigeria, asked in 1877: "What profit is there to us for girls?". They felt that female education was not profitable because "they cannot trade on board ships when they grow up only live in the house" (Tasie (1978) as quoted in p.34). Evidence on trends in gender wage discrimination is discussed in Blau and Kahn (2000), and Oostendorp (2009) presents evidence of wage and earning discrimination against women in the labor market.
} 
activity. We also find the long-run effect of missions on schooling to be smaller in railway locations. As with government schools, this result indicates that the effect of missions is largely in locations that would have been educationally disadvantaged, as railways in Nigeria were associated with an increased supply of schools (Okoye et al., 2019a). We do not find the effect of missions to vary along all other initial factors we examine that could serve as proxies for demand for education or economic development. These factors include being in Northern Nigeria, proximity to the coast, early urbanization and population density, political centralization of the majority ethnic group, crop suitability for important colonial-era crops (cocoa, cotton, rubber, groundnut), general land suitability, and the presence of petroleum deposits. Overall, the results support the hypothesis that missionary investments in education had the greatest impacts in local areas that would not have received schools otherwise, and that initial demand for education does not matter on the margin for these long-run impacts. ${ }^{6}$

Lastly, and importantly, we show that historical missionary activities contributed to a reversal of fortunes in Northern Nigeria. Using discontinuities around the border of provinces where missionary activity was restricted by the British colonial administration, we find that these provinces were more prosperous in the past, with centralized governance institutions and well developed tax and legal systems. $^{7}$ However, these areas are poorer today and mired in significant conflicts, especially the notorious Boko Haram conflict led by a group known for its opposition to Western education (see Elkaim (2012a), Thurston (2017)). We demonstrate that individuals living in these restricted areas are less educated and less wealthy today than individuals residing just outside of these areas. We show that this reversal of fortunes is a direct consequence of missionary activity; it is not driven by other colonial investments as we do not find the colonial railway, hospitals, presence of a township, and government schools to vary between the restricted and other areas.

\section{Contributions to the Related Literature}

Our study contributes to the broad and still growing literature on the historical roots of comparative economic development (see Nunn (2020) and Michalopoulos and Papaioannou (2020) for excellent literature reviews). In the African context, this literature has emphasized the importance of three major historical events, which are the transatlantic slave trade (Nunn (2008); Nunn and Wantchekon (2011); Obikili (2015); Okoye and Pongou (2014); Okoye and Pongou (2017); Bertocchi and Dimico (2019); Gershman (2020)), European missionary activities (Gallego and Woodberry (2010); Nunn (2014); Wantchekon et al. (2015); Dev et al. (2016); Fourie and Swanepoel (2015); Jedwab et al. (2018a); Cagé and Rueda (2020); Okoye (2021)), and colonization (Acemoglu et al. (2001); Archibong and Obikili (2020); Huillery (2009); Anderson (2018); Mabeu and Pongou (2021); Canning et al. (2021); Brodeur et al. (2020)). Other works have studied the long-term effects of missionary activity outside of Africa (see, e.g., Valencia Caicedo (2019) on South America,

\footnotetext{
${ }^{6}$ Put differently, if missions went to places where the demand for education was generally higher or with better development potential, and ignored places with lower demand, then areas with missions should perform better regardless of the presence of government schools. The fact that the presence of government schools blunts the marginal effect of missions demonstrates that the supply of schools (by the government or missions) is important.

${ }^{7}$ These were the administrative and institutional features that the colonial administration believed were worth protecting from missionary interference (Tibenderana, 1983a), and were important for governance in the colonial period.
} 
Calvi et al. (2020) on India, Bai and Kung (2015) on China, Woodberry (2012) on several regions including Africa, Asia, Latin America and Oceania, Waldinger (2017) on Mexico, etc.).

All studies documenting the long-term effects of missionary activity in Africa have primarily focused on average impacts. We believe that our paper is one of the few to document significant heterogeneities in these effects along gender, religion, and historical supply of education by the colonial government. In so doing, we have uncovered some key channels through which European missions have had a sustained effect on human capital formation in Africa. This analysis also establishes that the supply of, rather than the demand for, education is the main mechanism through which the effect of missions operates. Our analysis complements a few other studies that have documented the heterogeneous impacts of historical shocks in Africa. Okoye et al. (2019a) show that colonial railroads in Nigeria have larger short-term and long-term effects in regions that had no pre-railway access to ports of export. Michalopoulos and Papaioannou (2014) show that the effect of national institutions on local economic development in Africa is only present in locations closer to the capital city. Canning et al. (2021) document the effects of colonial origins and population policies on fertility and local economic development in Africa, and find that these are stronger in areas with low market access. Our paper differs from these studies in its scope, research question, and findings.

We also differ from previous studies on the long-term effects of missions in considering new outcomes, notably fertility. In this respect, our analysis contributes to a new area of research that seeks to understand Africa's high fertility rates through the lens of history. As far as we know, Canning et al. (2021) is the only study in this area. While their study examines differences in fertility outcomes between countries with different colonial origins, we investigate within-country variation instead. Indeed, although the literature on African fertility has highlighted differential trends within countries, there has been little research about how these differences relate to historical factors. We find that historical missionary activities have a causal impact on fertility preferences and number of children. Given the documented positive effect of low fertility on female labor participation and economic development (Galor and Weil (1999), Galor and Weil (2000), Bloom et al. (2009a)), our analysis highlights another channel through which missionary activity has had a sustained local economic impact.

Our findings also have implications for the importance of opportunities for human capital accumulation, in addition to institutions, for the reversal of fortunes in Africa upon European contact (Acemoglu et al. (2002a)). Our analysis reveals that the need to maintain the effectiveness of indirect rule among ethnic groups with stronger pre-colonial institutions and greater pre-colonial development resulted in missionary activities being severely restricted in some Emirates of Northern Nigeria. We find that individuals in those historically restricted areas are significantly less educated and poorer today compared to their counterparts living just outside of these areas. This reversal of fortunes is shown to be a direct consequence of differential exposure to missionary activity.

Finally, our research design, which is based on a fuzzy RDD framework, directly addresses some endogeneity problems suspected to invalidate findings about the long-term economic effects of historical missions in Africa (Jedwab et al. (2018a)). A comparable methodology is Wantchekon et al. (2015) who use data from Benin to find that villages with missionary schools in the colonial period have higher levels of schooling today, compared to neighbouring villages with no missionary schools. Also, focusing on a single country as some other studies examining the long-term effects of historical events (Wantchekon et al., 2015; Acemoglu et al., 2014) accounts for hard-to-observe country level heterogeneities and facilitates identification. 


\section{Historical Background}

In this section, we present a brief discussion of the factors behind the distribution of mission stations in Nigeria, focusing on reasons why missionary activities were restricted in some areas of Nigeria. More detailed histories of missionary expansion in Africa and Nigeria may be found in Nunn (2010) and Okoye and Pongou (2014), respectively.

\subsection{Motivations for Missionary Activity}

Christian missionaries arriving in nineteenth century West Africa were keenly aware of the failures of earlier missionary activities, as well as the tremendous gains Islam had made in the West African interior. Spurred on by T.F. Buxton's The African slave trade and its remedy published in 1839, and the evangelical revival of John Wesley in Britain, missionaries were eager to reach as many African societies as they could. This grew out of the perceived need to advance civilization, curb the slave trade, and counteract the spread of Islam.

The work of T.F. Buxton was instrumental in convincing the British public to finance the Niger Expedition of 1841 , at a cost of about $£ 100,000$ (about $£ 280$ million in 2010 ). The expedition failed and of the 145 Europeans on board, 130 contracted malaria fever and 40 had died within a year ((Sundkler and Steed, 2000, p.224),(Ajayi, 1965, p.7-8)). This failure underlined the necessity of having African converts who would be able to carry on the missionary work from the coasts to the hinterlands, creating an important link between education and missionary activity, in addition to schools being utilized as a tool for evangelization (Ajayi, 1965; Tasie, 1978, Chapter 1).

In studying the long-term effects of missions, we note that we do not distinguish between Protestant and Catholic missions in Nigeria, because all missions aggressively adopted schools as the primary method for gaining converts in Nigeria and schooling efforts by Catholic missions were even more successful in Nigeria. Catholic and Protestant missions actively competed for converts using schools and health services as enticements for young children and their parents. In 1886 a C.M.S. schoolmaster complained that the "Catholic Spiritans have taken from our school about a dozen children over whose parents they had exercised some influence" (Okwu, 2010, p.127). Another complained in 1895 that "the Romanists...seek to win our children to their schools, they visit the houses of our converts, they try to bribe the most able of our teachers" (Okwu, 2010, p.111). In fact, at some point in the early twentieth century, enrolment in Catholic schools was greater and outpaced enrolment in Protestant schools by a significant margin in Eastern Nigeria (see (Ayandele, 1966, p.302) and Table 1 in (Okwu, 2010, p.164)).

\subsection{Missionary Activity in the Interior and Colonial Policy}

\section{Restriction of Missions}

Missionary activities in Nigeria naturally began at the southern coasts, which was the point of entry for missions, and proceeded into the interior as in Figure 1. While missionary work was expanding from the southern coasts into the interior, the Islamic Emirates, notably Sokoto and its affiliated Emirates, were pushing south towards the coast. The Sokoto Emirates (Caliphate), which was founded in 1804 as the result of a Jihad intended to purify Islamic practice in the region, included over 10 million people over 30 Emirates in a confederation that extended across parts of West and 
Central Africa at its peak (Burdon (1904); Last (1967)). The seats of the Sokoto Caliphate and the much older Kanem-Borno Empire were located within the restricted provinces (as shown in Figure 1).

Hence, given the advance of Christianity from the coast and Islam from the north, the areas south of the restricted provinces in Northern Nigeria, which also contained several Emirates that formed part of Sokoto and Borno, formed an area of active Christian and Islamic missionary activities with potential for conflict and undermining of governance through traditional rulers (indirect rule). ${ }^{8}$ The reaction of colonial officials to this issue was the restriction of missionary activities in the core of Sokoto and Borno in order to strengthen the power of Islamic rulers in the Emirates. As Major J.A. Burdon put it in a report (Burdon, 1904, p. 649):

What is the attitude of the British Administration towards the Emirates? Briefly, it is construction not destruction. Our aim is to rule through the existing chiefs, to raise them in the administrative scale, to enlist them on our side in the work of progress and good government. We cannot do without them. To rule directly would require an army of British Magistrates, which both the general unhealthiness of the country and its present poverty forbid.

Colonial administrators, therefore, sought to maintain and strengthen the power of the rulers of the Islamic Emirates. As a result, the first half of the colonial period in Nigeria (1900-1930) can be summarized as a period of strict restrictions on the activities of missions in many areas of Northern Nigeria. This amounted to a policy of non-interference with Islam in Emirates within the restricted areas, and restriction of Christian missions in other areas (Ubah, 1988). Throughout the period of the Caliphate's existence, they justified their right to rule on the basis that they would uphold Islamic law and maintain the Islamic character of the region (Nwabara, 1963). This is one of the primary motivations behind the British policy of religious non-interference in the north. If the British insisted on permitting unrestricted missionary activity in the Sokoto Caliphate, it would undermine the legitimacy of the Caliphate's Emirs. Such a loss of legitimacy could threaten the Emirs' control over the political situation, putting into jeopardy their ability to govern the region on behalf of the British, as well as their willingness to do so (Abdurrahman, 2012).

Therefore, the restriction of Christian missionary activities at the heart of the Emirates while permitting missions to operate in other parts of the Emirates and Northern Nigeria presented a sort of compromise. The policy banned any attempts to convert the Emirates' Muslim populations (Ubah,1976), effectively restricting Christian missions from operating in the Emirates' predominantly Muslium areas, without the permission of the local Emir (Ubah, 1988). However, the British did allow missionaries to operate in the Emirates' predominantly non-Muslium areas. ${ }^{9}$

While these limited missionary activities were technically permitted by the British, their activities were often discouraged if they became seen as a threat to the local Emir. For example, the aforementioned mission in Zaria was eventually thrown into jeopardy after the missionaries erected a new church without consulting the Emir. The ensuing controversy forced the mission to relocate

\footnotetext{
${ }^{8}$ Key Emirates outside the restricted areas include Bida, Ilorin, Kontagora, and Adamawa.

${ }^{9}$ For examples, the colonial administration permitted the establishment of missions in several townships in the core Emirates of Kano and Zaria. This was justified on the grounds that the townships in question were primarily inhabited by non-Muslim migrants from various parts of West Africa, and the missions were erected outside of the territory under the executive control of the Emirs (Ubah, 1988).
} 
from the city (Ubah, 1988). Similarly, the mission station in Kano was moved outside the city in order to avoid missionary contact with the native population (see pages 146-152 in Ayandele (1966)). There were also cases of ethnic groups within the restricted provinces who had their requests for Christian missionaries turned down on the grounds that it would create disloyalty to the Muslim rulers (Sundkler and Steed, 2000, p.256). The colonial government's attitude towards missionary activity in the North is perhaps best illustrated by the statement below:

Personally I should like to see the Missions withdraw entirely from the Northern States, for the best missionary for the present will be the high-minded clean living British Resident. - Percy Girouard, Governor of Northern Nigeria (1907-1909), as quoted in (Ayandele, 1966, p.116).

The effect of these restrictions was to effectively limit the expansion of missions into the restricted provinces. We use variation in missionary activities around the border of areas where missionary activities were banned to identify the long-term effects of missions on education and other outcomes. This is valid under the assumption that colonial policy is the reason for the discontinuity in missionary activities between areas just within and outside the restricted provinces. We provide historical support of this below, and empirical evidence in Section $4 .{ }^{10}$

\section{Christian Missions and the Northern Emirates}

It is important to note that Christian missions were eager to push into the Emirates of Northern Nigeria, motivated by the need to curb the spread of Islam. Access to the area was also not a factor, because by 1900, the British colonial administration already had a significant presence in Northern Nigeria and the area was accessible to European traders and missionaries (Ayandele, 1966, p.120-126). By 1911, there was a rail line going from Lagos to Kano in the heart of the North, and by 1926, another line went from the coast to the capital of Northern Nigeria. Furthermore, Europeans had made contact with the Northern Emirates as early as 1821 (Sundkler and Steed, 2000, p.254), and attempted to establish a mission station in the Illorin Emirate as early as 1855. There were various mission stations established in Muslim areas of Northern Nigeria between 1855 and 1900 (Ajayi, 1965, p.97). These include the establishment of mission stations in parts of the Emirate at Bida, Kontagora, and Zaria. Led by the evangelist Dr. Walter Miller, several European missionaries also preached in the large cities of the Emirates without the government's approval (Ayandele, 1966, p.133).

As a result, Christian mission agencies often accused the administration of being pro-Islam, however the administration continued to maintain the policy of restrictions on missionary activities. As Lord Salibury said in an address to the Wesleyan Missionary Society in 1900, "You will not convert them... and the danger of creating great perils and producing great convulsions, and it may be bloodshed..., is a danger you must bear in mind" (as quoted in (Ayandele, 1966, p.137)). This was a conflict the colonial government wanted to avoid as much as possible, as they believed that allowing missionary activity in a region dominated by Islam would be tantamount to preaching at gunpoint (Barnes, 1995). Hence, the absence of missions in the restricted areas was not driven by the unwillingness of missions to move into those areas, but as a result of restrictions imposed by the government.

\footnotetext{
${ }^{10}$ We show that the areas just within and outside the restricted areas are similar along a wide range of precolonial and geographic characteristics.
} 


\section{Demand for Education in the Restricted Areas}

The absence of missionary activities in the restricted areas could also be due to the lack of a demand for education; that is, missions did not go into these areas because they will not be able to entice converts using schools. We argue that this is not the case for a number of reasons. First, we have provided earlier examples of demand for education (and missions) from ethnic groups within the restricted provinces. An agent of the Wesleyan mission from the Kanem-Borno Emirate had pleaded with the mission to send missionaries to the area as early as 1879 (Ayandele, 1966, p.118). Second, Tibenderana (1983b) uses communications between Emirs within the restricted areas and colonial officials to document how requests for education facilities, and missions in some cases, were turned down by colonial officials. Therefore, while the Emirs might not have wanted Christianization, they dedicated a lot of (limited) resources to secular Western education. The lack of resources by the Emirs was due to the structure of indirect rule in Nigeria. While colonial officials governed through traditional authorities, who were independent in many ways, this independence did not extend to the use of revenues. The power to spend revenues collected by the Emirs was vested on the colonial Resident (Tibenderana, 1983b). ${ }^{11}$ As a result, education was largely at the hands of the colonial government in areas where missionary activity was restricted. Third, when we examine government schools, we do not find any differences between areas within and outside the restricted provinces (see Figure 4), indicating that the resistance of the Emirs was to Christian missions and not education, a point corroborated by Tibenderana (1983b).

The Emirs were well aware of the value of Western education and were eager to take advantage of the few opportunities provided by the colonial government. The Emirs even competed amongst themselves and rival families as to who could attend the limited schools, and routinely sent their sons and children of their allies. As the Superintendent of Education in Zaria, within the restricted provinces, put it (Tibenderana, 1983b, p.521):

No one understands the advantages of education at the school better than the Emir of Zaria [Aliyu] who has induced thirty-four parents and guardians to send their boys to school during the year... He wishes his own sons and proteges to have the benefits of a liberal education [but] he does not want the sons of rich traders, sons of men belonging to dynasties other than his own, or sons of men whom for various reasons he does not like, to have the same attainment as the sons of his own men.

The high levels of demand within the Emirates was underlined by Governor Lugard in the 1914 amalgamation report. Summarizing the state of education in the Northern Muslim Emirates, he concludes that "the high percentage of attendance (95.9\%) may be accepted as an indication of the keen interest of pupils and parents" (Colonial Office, 1914).

Hence, there was demand for Western education within the Emirates, and the Muslim rulers understood the value of Western education. In a bid to satisfy some of the demand for schooling in the North, the government decided to establish non-missionary government schools in the restricted areas (Sundkler and Steed, 2000, p.256). Nevertheless, the government's effort could not match the more organic community-led effort of the missionaries. As early as 1914, there were already 65,000

\footnotetext{
${ }^{11}$ For example, in 1917, the Sultan of Sokoto, the spiritual leader of all Muslims in Nigeria and head of the Sokoto Caliphate, was denied permission to spend $£ 69$ on schools for pupils whose homes were too far away from the established government school. This is from an Emirate with annual revenues of £40,000 with additional annual contributions of $£ 8,000$ to the War Fund (Tibenderana, 1983b).
} 
primary school pupils in the South, but just 2,100 primary school pupils in the North with roughly the same population. In a country where $97 \%$ of the student population were in mission schools as at 1942, the negative effects of this infrastructural deficit was already apparent in significantly lower literacy rates in Northern Nigeria as at 1952 (Barnes, 1995; Prothero, 1956).

\subsection{Summary}

In summary, demand for education was not lacking in the Emirates of Northern Nigeria as the value was apparent given how quickly the Emirates were subdued by the British. Further, several mission societies were eager to push into the Emirates in order to evangelize and counter the spread of Islam. However, the colonial policy of non-interference with the institutions of the Emirates, built on religion, severely restricted the spread of missions and effectively prohibited their activities in the core Emirates. Applications by Christian missions to enter these areas were routinely turned down by colonial officials (Barnes, 1995). We exploit discontinuities in missionary activities around the border of the Emirates where missionary activities were prohibited to credibly identify the long-term effects of Christian missions.

\section{Data}

The dataset is built on multiple rounds of the Nigeria Demographic and Health Surveys (DHS), specifically the surveys conducted in 1990, 2003, 2008, and 2013 (NBS and ICF International, 2018). The DHS is a survey implemented in several countries with a focus on obtaining comprehensive information on representative households and selected individuals within the household. The DHS provides data on years of schooling, level of education completed, and several demographic variables for individuals and the households in which they live. The DHS provides information on location and ethnicity for over 100,000 individuals, between the ages of 15-59. We use data on individual characteristics, location, and ethnicity, to build the data used in the analyses. The primary unit of analyses in our data are local government areas (local area), which is the second-level administrative division in Nigeria. Overall, we have information on over 120,000 individuals, from 2430 DHS clusters, spread across 713 (out of 774) local government areas in Nigeria.

\section{$3.1 \quad$ Outcomes}

Our analysis focuses first on the long-term impacts of missions on education, an area in which missionaries invested significantly in Nigeria, accounting for the dominant share of school pupils in the colonial era (Ajayi, 1965). We obtain information on years of schooling, literacy, and the probability of completing different levels of education, for individuals within a local area. Second, we use data on household wealth and urbanization, as measures of general household wellbeing, and collect information on fertility (actual and ideal) as measures of broader sociodemographic change. Fertility behaviors are closely related to human capital accumulation choices, and they are an important driver of economic development (Galor and Weil (1999), Galor and Weil (2000), Bloom et al. (2009a)); therefore analyzing the effect of missions on fertility behavior in the context of Nigeria is likely to provide a new mechanism through missions have had lasting effect on education and local economic development in this country. 


\subsection{Historical Exposure to Missions}

We measure historical mission exposure as 1) proximity to a mission station; and 2) for the bordercontinuity design, we define historical exposure as the presence of a mission station within the local area. Data on the location of mission stations in Nigeria are taken from two sources. The first is a map published by Roome (1925) showing the location of primary mission stations (Protestant and Catholic) in Africa in 1924. The map, which is highly regarded as accurate, is also used in Nunn (2010), and several other studies. ${ }^{12}$ We combine the map from Roome (1925) with another map, from Ayandele (1966), which provides the location of mission stations in Southern and Northern Nigeria as at 1928. Information from both maps were manually cross-checked, and in order to minimize the risk of double-counting, we add a mission station from Ayandele (1966) if it does not belong to the same local government area as the mission station in Roome (1925). There is significant overlap in both maps, but the map from Ayandele (1966) provides information on 30 additional mission locations (out of 159 ) in Nigeria. ${ }^{13}$

We match location names in the DHS to a map of local government areas in modern Nigeria from GADM (2019), and the map of mission stations in 1928 described above. Using this information, we are able to compute the distance between each local government area and a mission station in 1928, and an indicator variable for the presence of a historical primary mission station within a local government area. In general, we count a local area as exposed to a mission station if it lies within 0 to $40 \mathrm{~km}$ of a primary mission station which represents the range mission stations might be able to cover and accounts for the growth of outstations to adjoining areas. ${ }^{14}$ However, for the analyses around the border of restricted provinces, we define historical exposure as the presence of a mission station within the local area, because the movement and expansion of missionaries were restricted in these areas.

A map of primary mission stations in 1928 Nigeria is shown in Figure 1. The map also highlights Southern and Northern Nigeria, as well as the border of the restricted provinces. While we see some continuity in mission station as we move from southern into northern Nigeria, the number of missions stations drop significantly at the border of the restricted provinces. This discontinuous decline in the number of mission stations at the border of the restricted provinces is what we exploit in our regression discontinuity design.

\footnotetext{
${ }^{12}$ Some authors make the distinction between Catholic and Protestant missions, arguing that Protestant missions invested more heavily in education; but this distinction is not particularly relevant in Nigeria as both mission types actively competed for converts using education as an inducement. In fact, in the Eastern part of Nigeria, enrolment in schools run by Catholic missions outpaced that of Protestant missions (Ayandele, 1966, p.302), which is consistent with the results in Gallego and Woodberry (2010).

${ }^{13}$ The data in Ayandele (1966) comes from missionary reports and information from the Blue Books on Ecclesiastical returns. Primary mission stations are utilized for two main reasons. First, they are less prone to measurement errors associated with the thousands of outstations that are established by missionaries linked to primary stations. Secondly, primary stations are also relatively more permanent establishments when compared to outstations that are always shifting. For example, when we examine the Ecclesiastical Returns in the 1928 Colonial Blue Books for Nigeria, we find that the 159 primary mission locations were associated with over two thousand outstations. Comparing information across years also indicates that these outstations were not permanent but changed from year to year depending on availability of ministers and local resources.

${ }^{14}$ Wantchekon et al. (2015) restricts the distance to $20 \mathrm{~km}$ for access to mission schools, which is plausible given that access to schools is limited by distance.
} 


\subsection{Control Variables}

Given that the location of mission stations might not have been random (Jedwab et al., 2018b), and possibly driven by a number of geographic, climatic, and socioeconomic factors, we include a large set of control variables in order to account for this possible endogeneity, following closely the significant factors identified in Jedwab et al. (2018b) and Michalopoulos and Papaioannou (2018). These variables, their sources, and how they are calculated, are briefly described below.

\subsubsection{Colonial Investments and Population Conditions}

The first set of control variables we include are colonial-era investments that might have been correlated with missionary expansion and future development. They comprise data on the presence of transportation infrastructure, including the colonial railway (as at 1928), an expressway (as at 1960), and a major seaport (as at 1928), in the local area. Data on transport infrastructure are taken from Okoye et al. (2019b). From the Colonial Blue Books (Preston, 2006), we also obtain information, as at 1928, on the presence of government hospitals, an official township (urban area with European residents), and the presence of a government school (as an alternative to mission schools). In addition to the above, we use estimates from Klein Goldewijk et al. (2011) to compute urbanization rate in the local area at an even earlier period, 1900, along with total population, and population density. We combine these with data from Jedwab and Moradi (2016) on the presence of a city within the local area in 1900. These variables are intended to capture early development and the presence of other colonial investments that might be correlated with missionary presence, future education and development outcomes.

\subsubsection{Geographic and Agricultural Conditions}

Our analysis also controls for potential geographic, climatic, and agricultural differences between local areas that might have driven missionary presence. These include information on mean precipitation from Harris et al. (2014), land suitability for agriculture and major colonial-era crops (cocoa, cotton, groundnut, oil palm) from Fischer et al. (2008) and Okoye et al. (2019b), elevation and ruggedness (Hastings and Dunbar, 1993), the presence of a major river (Earth, 2018), and malaria ecology using data from Gething et al. (2011). We also calculate the Euclidean distance of the local area to the coast, as a measure of exposure to colonial-era trade, distance to the country's borders, and the total land area of the local area.

\subsubsection{Ancestral Ethnic Heritage of Local Area}

We also compute the ancestral heritage of the local area using the methodology developed in Giuliano and Nunn (2018). Basically, we want to account for the characteristics of the ethnic or cultural group that occupied the local area in the pre-colonial and early colonial era. In order to accomplish this, we combine the map of local areas with a map of ethnic homelands from Murdock (1959). We identify the dominant ethnic group in each area using a population-weighted land area based on population weights from Klein Goldewijk et al. (2011). We find that about $94 \%$ of all local areas have one majority ethnic group (greater than $50 \%$ of historical population-weighted land area), and $74 \%$ of all local areas have one ethnic group making up more than $75 \%$ of its population-weighted land area. This indicates that most local areas closely align with specific 
ethnic groups from the Murdock (1967) dataset. Hence, we assign each local area the characteristic of the dominant ethnic group within the area, and for local areas where there is no dominant ethnic group (5\% of the total), we take the median characteristic. This is what we call the ethnic heritage of the local area, and helps to account for the possibility that some ethnic groups might have been more welcoming to missions and also future development.

From the Ethnographic Atlas in Murdock (1967), we collect information on a number of ethnic group characteristics. We include variables that have been shown to be related to education and other measures of development (see survey in Michalopoulos and Papaioannou (2018)). These include the intensity of agriculture, settlement patterns, judicial hierarchy within the group, centralization, class stratification, monogamy, composition of the marital household, female bias in agriculture, and the payment of a bride price.

The variables are summarized in Table 1 . About $20 \%$ of local areas have at least one mission, but $61 \%$ of local areas are within $20 \mathrm{~km}$ of a mission station underlying the level of missionary activity in colonial Nigeria, one of the most active in West Africa (Sundkler and Steed, 2000). Government schools and the railway line were also present in about $21 \%$ of local areas, and only about $4 \%$ of areas were considered townships or cities. Looking at ethnic characteristics, we find that about $94 \%$ of all local areas have one majority ethnic group. All variables are included as controls in the estimation, and we outline the empirical framework next.

\section{Empirical Framework}

We estimate the relationship between the presence of missionary activities in an area on levels of educational attainment, fertility, and household wealth, in the area today. We focus on local government areas in modern Nigeria, and measure historical missionary presence as the presence of a mission station and distance to a mission station, as explained in Section 3. The presence of a primary mission station in a local area indicates that missionaries worked in that area, but it is also possible that missionaries worked in local areas without a primary station creating outstations in neighbouring areas. Therefore, we include the distance measure to account for this possibility. ${ }^{15}$

\subsubsection{Baseline Strategy and Results}

Our baseline identification strategy regresses total years of schooling on historical missionary activities within a local area, according to the equation below:

$$
S_{i, a, d, N}=\alpha_{N}+\beta_{1} M_{a}+\sum_{d \in D} \beta_{1}^{d} M_{d}+\mathbf{X}_{\mathbf{a}}^{\mathbf{c}} \lambda+\mathbf{X}_{\mathbf{a}}^{\mathbf{g}} \boldsymbol{\Pi}+\mathbf{X}_{\mathbf{a}}^{\mathbf{p}} \boldsymbol{\Gamma}+\mathbf{X}_{\mathbf{a}}^{\mathbf{e}} \boldsymbol{\Omega}+\epsilon_{\mathbf{i}, \mathbf{a}, \mathbf{d}, \mathbf{j}} .
$$

Equation (1) models the schooling attainment for individual $i$, living in local area $a$ that is within some distance $d$ from a primary mission station in 1928, and either in northern or southern Nigeria $\left(\alpha_{N}=1\right.$ if in the North). Historical missionary presence is measured using an indicator

\footnotetext{
${ }^{15}$ The distance measure also helps to alleviate concerns about measurement errors associated with the precise location of a mission station. Jedwab et al. (2018b) finds that mission locations are measured with error and are often not in their geocoded locations, but a geocoded mission station is most likely to fall between 0-40 km of the geocoded location. Further note that our data is cross-checked with the map by Ayandele (1966) that provides location names and avoids the location errors associated with Roome (1925).
} 
variable for the presence of a mission station within the local area, $M_{a}$, and distance from a primary mission station, $M_{d}$. We use discrete non-overlapping distance categories, with $d \in D=$ $\{0-20,20-40,40-60,60-80,80+\}$. The model controls for a number of variables that might have driven the location of mission stations and possibly related to future development (Jedwab et al., 2018b). These include controls for colonial investments (c), geoclimatic (g), population (p), and ethnic (e), and characteristics of the local area, which are described in Section 3. Standard errors are clustered by local area.

\section{Fuzzy Regression Discontinuity Design}

In order to strengthen the internal validity of our results, we exploit the history of mission expansion in colonial Nigeria to identify the long-term effects of missionary presence. Specifically, missions were effectively barred from operating in the northernmost Emirates of the region (see Figure 1 and discussions in Gbadamosi (1967); Tibenderana (1983b); Ubah (1988)). ${ }^{16}$ Missions that were already established were encouraged to move out of major towns or restricted to areas occupied by non-locals, and requests by missionaries and locals for more missions were consistently denied as a matter of policy (Gbadamosi, 1967; Ubah, 1988).

We digitize the map of colonial Nigeria, shown in Figure A1 to recreate the provinces where missionary activities were restricted and match them to current local areas in Nigeria. According to Gbadamosi (1967) and the Annual Report of the Colonies for Northern Nigeria (Colonial Office, 1903, 1908), missionary activities were restricted in 6 provinces. These were Sokoto, Katsina, most of Zaria, Kano, Bauchi, and Bornu provinces. We match these provinces to local areas in Nigeria today in order to delineate the southern borders of the restricted provinces, shown using the dashed lines in Figure 1. ${ }^{17}$ In order to implement this strategy, we restrict the sample to local areas that are within a narrow distance from the border, using bands of $10 \mathrm{~km}, 20 \mathrm{~km}$, and $30 \mathrm{~km}$, respectively, recognizing the trade-off between bias and variance as the bands change (Angrist and Pischke, 2009). ${ }^{18}$

Our goal is to compare schooling attainment, and other outcomes, in areas just within the restricted provinces to local areas just outside, and relate this to differences in missionary activities as at 1928. We first provide evidence that the policy was relevant. Figures 3 and A2 show that the policy of restricting missionary activities generated a discontinuous change in the presence of missionary activities, and schooling attainment today, at the border of the restricted provinces. ${ }^{19}$ Further, in Figure A3, we demonstrate that this is a true border effect-no discontinuities in

\footnotetext{
${ }^{16}$ As explained earlier, several reasons were offered for restricting missions in these provinces. First, colonial officials wished to avoid the emergence of anti-colonial sentiments which colonial officials had blamed on "disgruntled intellectuals" emerging in parts of southern Nigeria. Secondly, because these provinces were led by Muslim Emirs, colonial officials wanted to maintain this status-quo, which could be disrupted by Christian missionary activities. Maintaining the status-quo also reduced the cost of administration, because the provinces could be governed through the Muslim chiefs and avoid any potentially turbulent changes.

${ }^{17}$ In modern Nigeria, the restricted provinces cover 11 of Nigeria's 36 states, namely Sokoto, Kebbi, Zamfara, Kano, Jigawa, Northern Kaduna, Katsina, Bauchi, Gombe, Yobe, and Borno, states.

${ }^{18} \mathrm{An}$ example looking at a $10 \mathrm{~km}$ band is shown in Figure 2.

${ }^{19}$ The model is fit using a 4th-order polynomial regression, where the coefficient on distance is allowed to vary depending on whether local areas were within or outside the restricted areas. The same discontinuity is observed even when we fit a linear function, as in Appendix Figure A2 and is not an artefact of the functional form.
} 
missionary presence are found for placebo borders that are just $50 \mathrm{~km}$ south or north of the true border. It is reassuring that there are no discontinuities where restrictions on missionary activities were not in effect.

Further, the strategy identifies the effects of missions under the assumption that these narrowly defined areas would have had similar outcomes in the absence of the restrictions on missionary activities, on average. This is plausible for a number of reasons. First, the borders of the restricted provinces were not decided by the locals or Emirs themselves, but by colonial officials, using rivers and disruptions in elevation as boundaries, even before the areas came under British control (Apata, 1992; Colonial Office, 1903). This is underlined by the fact that the Sokoto and Borno Emirates had allied Emirates within and outside the restricted provinces. ${ }^{20}$ Secondly, Figure 4 examines a number of colonial investments within and outside the restricted areas, and we do not find any significant difference in any other colonial investments and activities, ranging from the railway to townships and government schools, suggesting that the policy of restricting missionary activities was the major difference between these areas. Third, Tables 2, A1, and A2, provide evidence that there are no significant differences between areas within and outside the restricted local areas when the sample is restricted to areas within 10,20, and $30 \mathrm{~km}$ of the border, respectively. In Table 2, for example, we find that beside the presence of missions, there is no significant difference between local areas within and outside restricted provinces for 27 out of the 31 characteristics we examine. ${ }^{21}$ Specifically related to schooling, we do not find significant differences in the presence of government schools. Based on the above results, we may conclude that areas within and outside the restricted province would have had similar outcomes in the absence of the restrictions on missionary activities.

We estimate the effects of the fuzzy regression-discontinuity in the presence of missions at the border of the restricted provinces by two-stage least squares (Angrist and Pischke, 2009). The first-stage estimates the effect of being within the restricted province on the presence of missions within the local areas as at 1928, including all the control variables in Equation (1). We then use the predicted missionary activity to estimate the effect of missions on schooling attainment, and other outcomes, in the second stage. The sample is restricted to a narrow band within the border, and standard errors are clustered at the level of the local area. The next section presents the baseline results using the full sample.

\section{$5 \quad$ Missions and Schooling}

In this section, we present results on the long-run effects of missions on schooling, other measures of educational attainment, and heterogeneous effects. We begin with results using the full sample, and and then we present results using the fuzzy regression-discontinuity design in order to strengthen

\footnotetext{
${ }^{20}$ Examples of allied Emirates outside the restricted provinces include Bida, Illorin, Kontangora, and Yola, Emirates (Apata, 1992; Burdon, 1904).

${ }^{21}$ The exceptions are ruggedness, precipitation (associated with changes in elevation), centralization, and distance to the national border. While these might be statistical artefacts, some of the differences are meaningful. The difference in ruggedness and precipitation is consistent with the history of borders being drawn at places with sudden changes in elevation/terrain (rivers or hills, Apata 1992). Areas within the restricted provinces are more likely to be occupied by a centralized ethnic group, which is consistent with the fact that these areas were governed by Muslim Emirs prior to British colonization. Centralization has been found to be positively related to long-run development (Michalopoulos and Papaioannou, 2018), and cannot explain the discontinuous decrease in schooling within restricted provinces.
} 
the causal interpretation of our findings.

\subsection{General Results on Schooling}

Table 3 presents estimates of the relationship between historical missionary presence and total years of schooling today. The first column does not include any control variables, but only illustrates how the relationship between missionary activity varies by missionary presence and at different distances. We find a positive relationship between the presence of a mission, but this is driven entirely by the distance measure and not the presence measure - the coefficients on a mission station within $20 \mathrm{~km}$ does not vary significantly by the actual location of the mission station (6.2 vs 6.3). Further, the estimated relationship gets weaker with distance. As a result, we focus our attention on the distance measures for the baseline analyses, with local areas beyond $80 \mathrm{~km}$ excluded from the regression.

Of course, we cannot interpret the result thus far as causal because missionary activity might have been endogenous to future development potential (Jedwab et al., 2018b). Therefore, we proceed to include control variables in the rest of Table 3. The second column includes an indicator for being in the North of Nigeria, accounting for the well-known North-South gradient in schooling and development in Nigeria (Okoye et al., 2019b). This decreases the estimated relationship, but the same pattern remains - the estimated effect is largest for areas within $20 \mathrm{~km}$ of a mission station. Column (3) includes the full set of geographic controls in Table 1. We find that the point estimate decreases once again, decreases with distance, and is now only significant for areas within $40 \mathrm{~km}$ of a mission station. Columns (3)- (6) progressively add more controls for other colonial investments and early development, including railways and government schools as an alternative to mission schools, population conditions such as urbanization, and controls for the ethnic heritage of the area. The point estimates are robust to these additional controls, and only changes slightly with the added controls. Interestingly, distance to coast does not appear to be related to schooling outcomes conditional on region (North/South) and other geographic controls.

Overall, the results in Table 3 provide evidence of a robust positive relationship between missionary activities and years of schooling, conditional on the large set of controls we have included. An area within $20 \mathrm{~km}$ of a mission station in 1928 has about 2 more years of schooling, which decreases to 1.3 additional years for an area between $20-40 \mathrm{~km}$ of a primary station. There is a positive coefficient for areas further than $40 \mathrm{~km}$ away but they are not robust to additional controls. Nevertheless, it is still possible that the results in Table 3 suffer from omitted variable bias. We turn to the border discontinuity results in order to establish causality.

\subsection{Results from Discontinuity at Border of Restricted Provinces}

We present results from local areas within and outside the borders of the restricted provinces in Table 4. The results demonstrate that historical missionary activities within a local area continues to contribute to differences in educational attainment today. The first two columns only utilize local areas within $10 \mathrm{~km}$ of the border of restricted provinces, with no controls and the full set of controls added. In both cases, we find that the historical presence of missionary activities is associated with greater schooling attainment today. ${ }^{22}$ The same findings remain when the bandwidth is expanded

\footnotetext{
${ }^{22}$ The number of local areas is reduced as we add control variables, because data on ethnic heritage is not available for many local areas.
} 
to include areas within $20 \mathrm{~km}$ and then $30 \mathrm{~km}$ of the restricted provinces. The results in columns (2), (4), and (6), with the full set of control variables included, show that historical missionary activities in areas just outside the restricted provinces has led to about 3-4 more years of schooling compared to local areas just within the restricted provinces.

The first-stage estimates in Panel B provides similar results as in Table 2. Regardless of the bandwidth we examine, the results consistently show that being outside the restricted provinces increases the probability of a historical mission station by about $40 \%$. This is consistent with the history of excluding missions from the restricted provinces of Northern Nigeria. The Kleibergen and Paap (2006) tests of under and weak identification demonstrate that the first-stage is most strongly identified for local areas within 10 and $20 \mathrm{~km}$ of the border of the restricted provinces.

Overall, results using the discontinuity in missionary activities around the border of restricted provinces support the general finding in the previous section: local areas with missions as at 1928 have higher levels of educational attainment today. We argue that this result is causal because the discontinuity is a result of deliberate colonial policy and not other factors that might be associated with long-run development.

\subsection{Heterogeneous Effects by Initial conditions}

In this section, we investigate how the estimated effects of missionary activities vary by important factors that might have determined demand and supply for education. These include the presence of government schools in 1928 (an alternative supplier of education), being in Northern Nigeria, proximity to the coast, early urbanization and population density, presence of the colonial railway line, political centralization of the majority ethnic group, crop suitability for important colonial-era crops (cocoa, cotton, rubber, groundnut), general land suitability, and the presence of petroleum deposits. This analysis is intended to shed some light into why missionary activities are associated with increased levels of schooling. The model is estimated using the full sample, including the full set of controls in Table 3. We define exposure to historical missionary activities as being within 40 $\mathrm{km}$ of a local area, as this is the range at which consistent results are found in Table 3.

The results for heterogeneous effects are shown in Table 5, and visualized for a subset of initial conditions in Figure 5. The results from heterogeneity by the presence of government schools in column (1) imply that, conditional on access to a government school, historical exposure to missionary activities is not related to educational attainment in the present. This is evidence that the supply of schools is an important mechanism. While it is possible that government schools were strategically located, perhaps in the best locations, the fact that missions in areas with a government school do not have any additional positive impacts indicate that supply of schools (and not demand) is an important mechanism. Put differently, the long-run effect of missions on education attainment is primarily in locations that did not get government schools.

The effect of missions also vary according to the presence of railways, in column (6). While areas with railways developed more rapidly and attracted more schools (Okoye et al., 2019b), especially in Northern Nigeria, the results indicate that the effects of missions is lower for railway locations. As with government schools, this result indicates that the effect of missions is largely in locations that would have been educationally disadvantaged otherwise. This implies once again that the supply of, and not the demand for, education, due to local economic development, is responsible for the positive relationship between historical missionary activities and educational attainment. 
There are no significant heterogeneities for all other set of initial conditions we examine. The impact of missions does not vary by proximity to coast, early urbanization or population density, ethnic-group centralization, land suitability, and the presence of petroleum deposits, all of which would have made these locations more suitable for long-run development. Overall, the results here support the hypothesis that missionary investments in education had the greatest impacts in local areas that would not have received schools otherwise - as represented by the absence of government schools and colonial railway lines. We do not find evidence that the effect of missions varied by initial demand for education, as proxied by early urbanization, population density, and crop productivity.

\subsection{Heterogeneous Effects by Individual Characteristics}

The previous section presented results that demonstrate that the supply of schools by missionaries, and not demand for education, explains the positive long-run effect of missions on schooling. We investigate this further using insights from a model of the persistent effects of missionary activities on educational attainment developed in Appendix B.

One of the implications of the model is that the marginal impact of missionary activity would be higher for females compared to males, because missionary activity lowered education costs by increasing the supply of education infrastructure (Proposition 2). The intuition is that the marginal effect of increased schooling infrastructure on attainment would be stronger for females, because of the higher marginal benefit of schooling due to labour market discrimination. ${ }^{23}$ Therefore, if missionary activity primarily increased the supply of schooling infrastructure, we would expect larger estimated effects for females compared to males. The impacts would be larger for males if the effect is driven by demand for education. Further, the model implies that within groups with less historical missionary activities, and as a result lower education infrastructure today, the marginal effect of missionary activities on educational attainment would be larger. ${ }^{24}$ This is an immediate implication of decreasing marginal benefit to education for an individual, so that further reductions in costs would lead to smaller increases in educational attainment. We test this prediction by splitting the sample into Christians (high missionary activity) and Muslims. The results are in Table 6 .

The first column of Table 6 show results by sex, and provides evidence that the estimated effects of missionary activities are larger for females. Moving on to column (2), we find that the estimated effects are also larger for Muslim groups with less exposure to missionary activities. Restricting the sample to Christians in column (3), we continue to find stronger effects for females. In fact, the estimates imply that there is no effect of missions on male education when the sample is restricted to Christians. Column (4) restricts the sample to Muslims, and we do not find evidence of differential effects by sex.

These results are consistent with our model in which increases in the supply of schooling infrastructure leads to a greater increase in enrollment for females compared to males. The results

\footnotetext{
${ }^{23}$ Evidence on trends in gender wage discrimination is discussed in Blau and Kahn (2000), and Oostendorp (2009) presents evidence on the gender gap in earnings using cross-country wage data. This idea is also supported by the fact that the earliest school pupils were males, but female enrolment tended to grow as schooling infrastructure increased (Ayandele, 1966).

${ }^{24}$ We present results in a previous draft of the paper showing that areas with greater historical missionary activities tend to have more schools today. These results are available upon request.
} 
in Table 6 are, however, not fully consistent with a framework where the demand for education increases as a result of increases in taste or demand for schooling. If benefits rose as a result of increases in tastes for schooling, we would not expect to see a differential impact on males and females if there is no labour market discrimination, and should predict a greater impact on men in the presence of discrimination. ${ }^{25}$

In addition, compared to Christians, the increase in the supply of school infrastructure as a result of missionary activity was less in Muslim areas. In our data, we find the average number of mission stations per area of the individual's ethnic homeland is .68 if the individual is a Christian today, but only .05 for current Muslims. This implies that the marginal impact of missionary activity should be higher among Muslims, because average schooling infrastructure (mission stations) is lower in Muslim areas - this is where differences in historical missionary activities continue to matter. ${ }^{26}$ An added implication of the above finding is that we can rule out the nominal role of religion. While it is possible that Muslims living in close proximity to mission stations may acquire similar ethics even if they do not convert, the results indicate that gains in schooling could have been accomplished without mass conversions to Christianity. This somewhat justifies the colonial administration's policy of separating religion from education, but also indicts the administration for failing to adequately provide schooling alternatives.

\subsection{Other Measures of Education Achievement}

In this section, we provide results showing that the impact of missions is not restricted to years of schooling, but it extends to general literacy and the completion of basic education. Results in Table A3 show the long-term effects of historical missionary activities on literacy, and the probabilities of completing primary and secondary education, respectively. In column (1), we see that historical missionary activities are associated with a 20 percentage-point increase in literacy rates, which declines with the distance between the local area to a mission station. Historical missionary activities also increase the probability of completing basic education, as measured by primary and secondary school completion rates.

The effects on literacy show that missionary activities not only boost Western education achieve-

\footnotetext{
${ }^{25}$ While the evidence discussed above rules out a gender-neutral change in tastes for education, we cannot rule out gender-specific changes in tastes for education. A related interpretation of this finding is that it may be due to changes in gender values brought about by the Protestant ethic of missionaries. While some historical sources provide evidence that missionaries encouraged the education of females and children who were perceived as less "valuable," there is also evidence that education was biased towards men for economic reasons. For example, in the Niger Delta areas, more boys were sent to schools compared to girls because the Chiefs felt that, unlike girls, the boys could grow up to participate in trade. The Chiefs of Bonny, for example, asked "what profit is there to us for girls?" They felt that it was not prudent to send girls to school, because "they cannot trade on board ships when they grow up only live in the house" (Tasie, 1978, as quoted in p.34). This is, of course, additional evidence of the existence of labour market discrimination against females.

${ }^{26}$ Historical sources document the effects of missionary activity on schooling even among non-converts, primarily because of the demonstrable material benefits of schooling. In Lagos, for example, Yoruba Muslims who had initially resisted sending their children to mission schools out of fear of Christian influences, began to change their stance by 1900 and started to enroll in large numbers (Ayandele, 1966, p.300). Muslims in many parts of Northern Nigeria, on the other hand, did not have this option as a result of the prohibition of missionary activity in these areas, which is consistent with persistently lower levels of schooling amongst Muslims in Table 6.
} 
ments, as opposed to Islamic education that is prevalent in many parts of Nigeria, there is also a positive effect on literacy, a measure of learning that is common to both systems. Hence, the results are not just an indication of Christians enrolling in Western education while Muslims enrol in Islamic schools. ${ }^{27}$ There is a real effect on learning as measured by literacy rates.

\section{Missions, Demographic Change, and Reversal of For- tunes?}

\subsection{Missions and Fertility}

In this section, we investigate the long-term effect of missions on fertility in Nigeria. Interest in fertility behavior stems from the fact that it is an important determinant of female economic empowerment and economic development (Galor (2011); Bloom et al. (2009b)). It affects and is affected by education. Fertility remains very high in African countries despite a remarkable increase in female education and a steep decline in child mortality. An Average African woman had 4.8 children in 2016, compared to 2.4 children per woman for the world (The World Bank, 2016). While African fertility trends have attracted a significant amount of scholarship, a fact often overlooked is that there is a great deal of variation within and across African countries. Using DHS data from Nigeria, for example, an average woman in the northern part of the country has more than 6.5 children, versus 5 children per woman in the south. This means that while Nigeria is still in its early stage of demographic transition and remains somewhat trapped in a Malthusian regime, certain parts of this country are more advanced than others. In general, regional variations in fertility behavior have been attributed to differences in cultures, norms, and other kinds of historical institutions (Galor, 2011). However, there is almost no research that links historical institutions to fertility in Africa. An exception is Canning et al. (2021) who document the causal effect of colonial population policies on fertility differences between the former French and British colonies of Africa. There is no study that links historical institutions to within-country variation in fertility behavior, which is a gap we begin to fill in this paper. Analyzing the effect of missions on fertility behavior in the context of Nigeria will not only provide new insights into the differential pace of demographic transition in this country, but it will increase our understanding of why certain regions are lagging in terms of human capital accumulation.

We restrict the sample to females in the DHS sample who were asked and responded to questions about their fertility outcomes and preferences. Specifically, we include questions about total children ever born, number of living children (which also accounts for mortality rates), and number of ideal children (a measure of fertility preferences). We hypothesise that missionary activities will influence fertility preferences and outcomes, through their effects on education and health systems. We estimate the effects by OLS, and also using the fuzzy regression discontinuity design described in Section 4. All models include the full set of controls in Table 3 and standard errors are clustered at the local area.

Table 7 shows results using the full national sample. The results show that historical missionary activity within $20 \mathrm{~km}$ of a local area is associated with about .4 less total children born to women

\footnotetext{
${ }^{27}$ The literacy assessment in the DHS covers literacy in multiple national languages and forms of writing.
} 
in the local area, which is about $14 \%$ of the mean total children born to a woman. The estimated effect decreases for local areas within 20 and $40 \mathrm{~km}$, and 40 and $60 \mathrm{~km}$ of a mission station, just as we found for education impacts. In column (2), we find that historical missionary activities are also associated with a lower number of living children, but this effect is only seen for areas within $40 \mathrm{~km}$ of a historical mission station (our preferred measure of exposure). Column (3) estimates long-term impacts on fertility preferences, and the results continue to demonstrate a change in fertility preferences in favour of less children in areas with greater historical exposure to missionary activities.

Table A4, and Figures A4, A5, and A6, report results using the discontinuity in historical missionary activities around the border of restricted provinces, with the sample restricted to areas within $20 \mathrm{~km}$ of the border. As with the OLS results, we continue to find a significant change in fertility outcomes and preferences in areas with historical exposure to missionary activities. Exposure to missions is associated with a lower number of total and living children, and also a decrease in the number of ideal children. ${ }^{28}$ Overall, these findings indicate that missions have not only had long-term impacts on education, but also on fertility outcomes and preferences. This is an important component of demographic change.

\subsection{Missions and the Reversal of Fortunes?}

An interesting feature of our findings thus far, especially the results using discontinuities around the border of the restricted provinces, is that local areas that were relatively more advanced, with centralized governance institutions and well developed tax and legal systems, have less educational attainment and higher fertility rates today. These were administrative and institutional features which the colonial administration thought were worth preserving (Tibenderana, 1983b), and were important for governance in the colonial period. ${ }^{29}$ However, these areas of Nigeria are generally poorer today and have been mired in significant conflict, especially the notorious Boko Haram conflict led by a group known for its opposition to Western education (Elkaim, 2012b; Thurston, 2018).

Here, we investigate the extent to which the restrictions placed on missionary activities has contributed to a reversal of fortunes, as measured by household wealth, between areas within and outside the restricted provinces. Can the absence of historical missionary activities in areas with well developed institutional features partly explain why these places are relatively behind today? We shed some light on this question using data on past centralization and population density, as in Acemoglu et al. (2002b), in order to measure the areas' level of development prior to the colonial period. ${ }^{30}$ This is combined with data on household wealth, ranked nationally and as a factor score

\footnotetext{
${ }^{28}$ Note that the fuzzy RD results might not be immediately comparable to the OLS results, because we are looking at local impacts.

${ }^{29}$ See Last (1967) for a general description of the Sokoto Caliphate, which covered a portion of the restricted provinces. Adebayo (1995) and Tibenderana (1983b) describe the important features of these areas and their sophisticated administrative and tax collection systems. Bolt and Gardner (2020), for example, find that one province in the restricted area, Zaria, collected $£ 74,000$ in general tax, £10,000 in cattle tax, £5,000 in fees from Native Courts, and $£ 1,000$ from interest. These taxes built on pre-colonial, Islamic, systems of taxation. No province in southern Nigeria was able to collect much in taxes outside of customs duties (Colonial Office, 1908).

${ }^{30}$ Not only does pre-colonial centralization act as a proxy for past level of development, it is also an important predictor of current development in Africa (Michalopoulos and Papaioannou, 2014).
} 
computed from various proxies for wealth (Rutstein and Johnson, 2004).

In Table 8, we provide evidence that local areas within the restricted provinces were more developed in the past, but have fallen behind in the present. Columns (1) and (2) of Table 8 show that areas within the restricted provinces were more likely to have centralized political institutions and higher population densities relative to other parts of Nigeria. This is consistent with descriptions of some parts of these areas, especially the ability of the Native Authorities to raise revenues from direct taxes (Tibenderana, 1983b). However, looking at the present in columns (3) to (8), we find that local areas within the restricted provinces have substantially less schooling levels (columns 3 and 6). Furthermore, we find evidence of significantly lower wealth levels; especially when the sample is restricted to areas within Northern Nigeria, this is true regardless of whether we examine wealth rankings or the wealth score. ${ }^{31}$ Overall, the evidence here indicates that while areas within restricted areas were more developed in the past, they have fallen behind today, as measured by educational attainment and household wealth.

What is the role of historical missionary activities and other colonial investments in this reversal? Table A5 shows results from a regression of various colonial-era investments on an indicator for being within the restricted provinces. The results show significantly less missionary activities within the restricted provinces, which is true nationally as well as within Northern Nigeria. Further, we do not find evidence of any differences in other colonial investments ranging from the railway line to hospitals, presence of a township, and government schools. This points to a central role of missionary activities as a potential channel to understanding the reversal of fortunes within areas of Northern Nigeria.

Table 9 shows that controlling for historical missionary activities can explain some of the current relative backwardness. The Table demonstrates in columns (1) and (4) that the schooling gap decreases substantially once we control for the presence of historical missions, measured as being within $40 \mathrm{~km}$ of a mission station. Looking at the full sample, the results demonstrate that the wealth deficit within restricted provinces disappears and the sign reversed when we control for the presence of missions [columns (2) and (3)]. Similar conclusions are reached when the sample is restricted to areas within Northern Nigeria - the wealth deficit also disappears relative to the results in Table 8. The analyses above provides some evidence that colonial-era restrictions on missionary activities might be responsible for the relative backwardness of parts of Nigeria that were more prosperous in the past with important ingredients for future development - strong centralized institutions. The full implications of this finding is an important area for future research.

\section{Conclusions}

This paper documents the average and heterogeneous effects of historical Christian missionary activities on schooling, fertility, and household wealth in Africa's most populous country, Nigeria, and establishes that these activities have led to a reversal of fortunes wherein areas that were more prosperous and institutionally developed in the past are relatively poorer and less educated today. Combining contemporary individual-level data with a newly constructed dataset on mission stations in Nigeria, we find that areas with greater historical missionary activities have higher levels of schooling, lower levels of fertility, and higher household wealth today. Our preferred specification

\footnotetext{
${ }^{31}$ We restrict the sample to Northern Nigeria because the restrictions on missionary activities were only important in Northern Nigeria as shown in Figure 1.
} 
uses discontinuities in mission stations around the borders of areas where missionary activities were restricted, by the colonial administration, to show that the finding is indeed causal and not driven by initial demand for education or strategic missionary location decisions. We find the persistence of early advantages in educational infrastructure to be a key channel through which the effects have persisted. Consistent with theory, the effect of missions on current schooling is not found in areas with access to government schools, and is larger for population subgroups - women and Muslims-, that have historically suffered disadvantages in access to education. The restriction of missions from many areas of Northern Nigeria can explain why these areas that were more prosperous and institutionally developed in the past are relatively poorer today.

Our study makes some important contributions to the literature on the long-term impacts of Christian missions in Africa. First, we demonstrate that the effects of missions are indeed causal and not simply driven by missions locating in privileged locations. Secondly, by studying a country where missionary activities were widespread, from the coast to the interior, we are able to demonstrate that missionary impacts are not affected by several factors that could have driven initial conditions (infrastructural and agricultural), as would be the case in a world where mission stations simply reflected local demand. The importance of schooling infrastructure provided by missions is underlined by the fact that missions have no significant impacts in areas where the government established schools. Thirdly, we provide important context into the relatively poorer areas of Northern Nigeria, home to close to 100 million people. Our findings imply that while these areas was more prosperous and institutionally advanced than other parts of Nigeria, and indeed West Africa, colonial policies restricting missionary activities while not providing equivalent schooling infrastructure have largely reversed the early advantages of the region. The full implications of these policies, which were also replicated in parts of Northern Ghana and the Sudan, are an area of future research. 
Figure 1: Mission Stations in 1928 Nigeria (North and South) showing Restricted Provinces

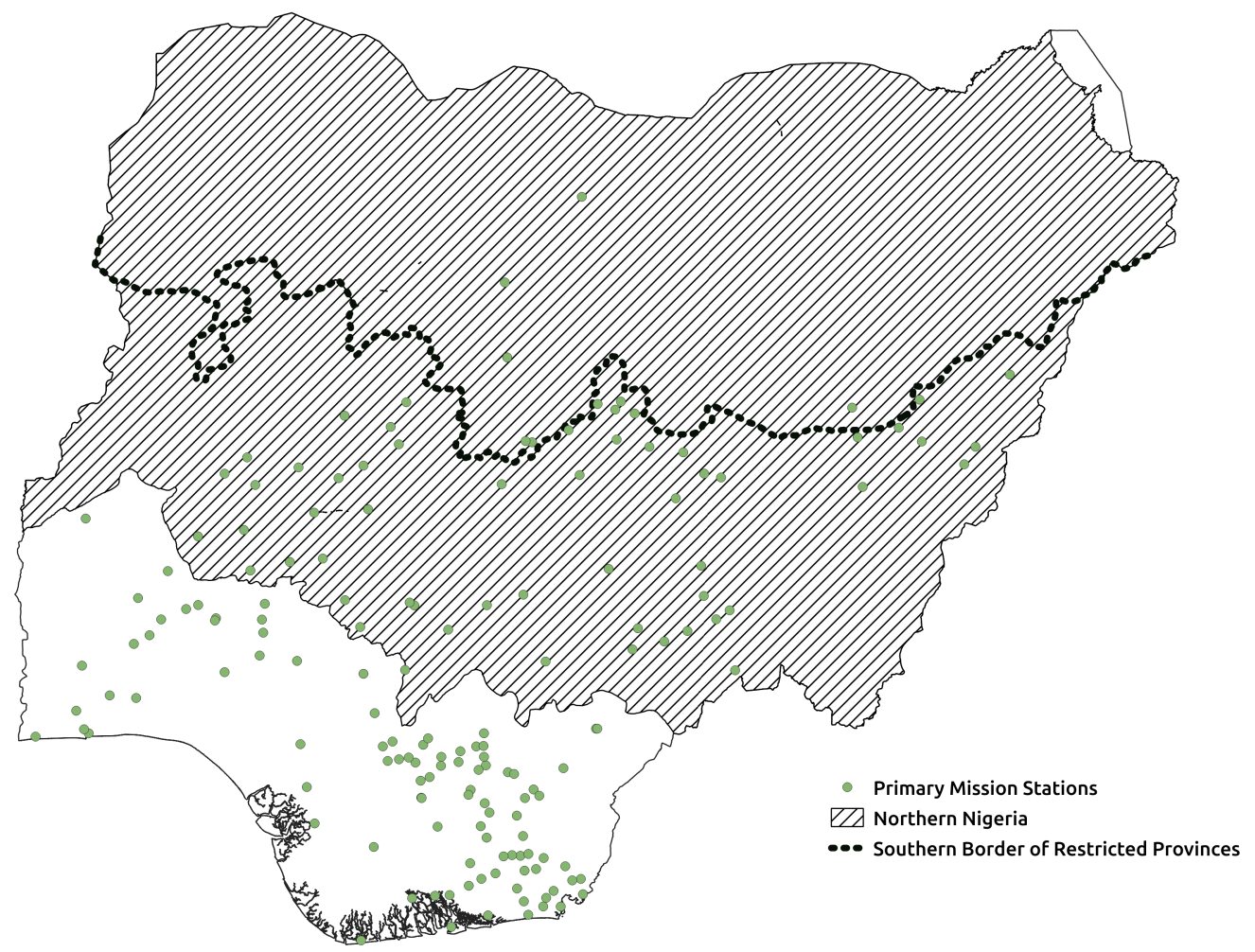

Figure 2: Local Areas and Mission Stations, Within and Outside 10km of Restricted Areas

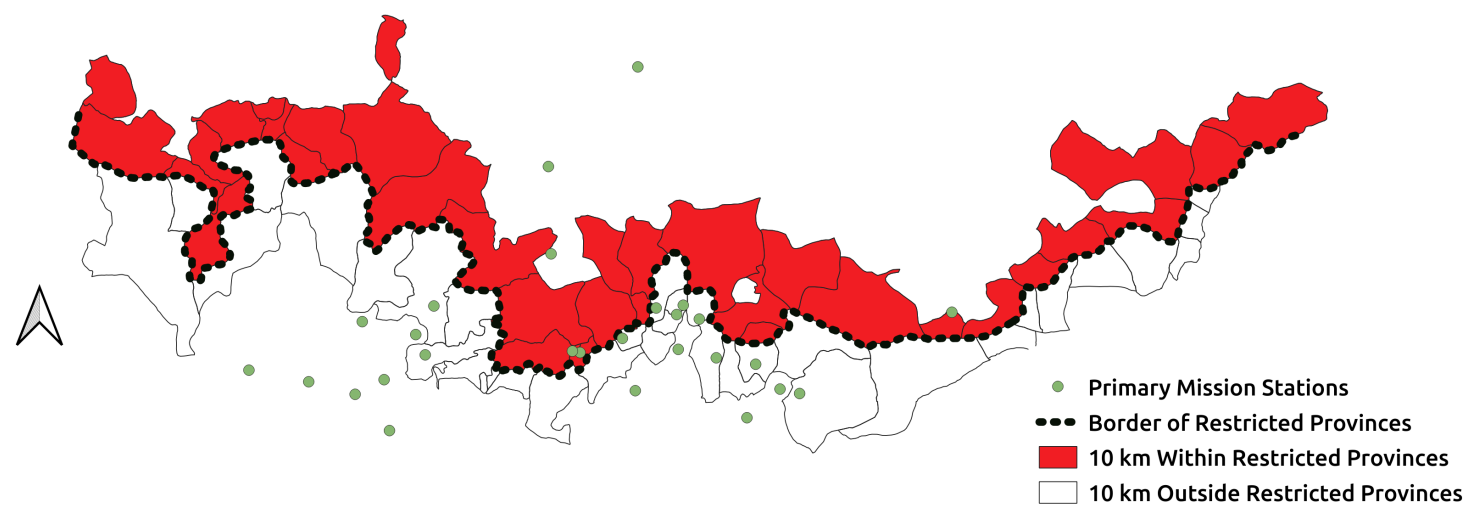


Figure 3: Discontinuity of Mission Presence and Schooling Within and Outside Restricted Areas

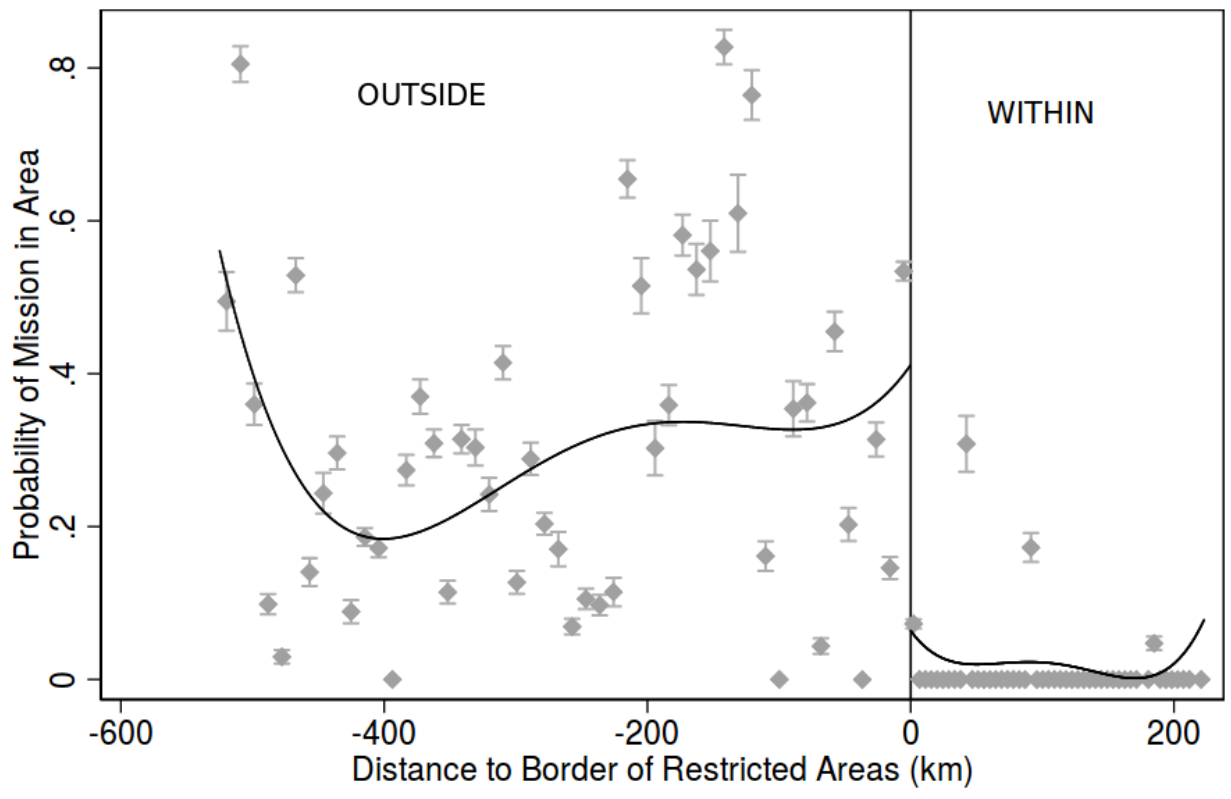

- Sample average within bin $\quad$ Polynomial fit of order 4

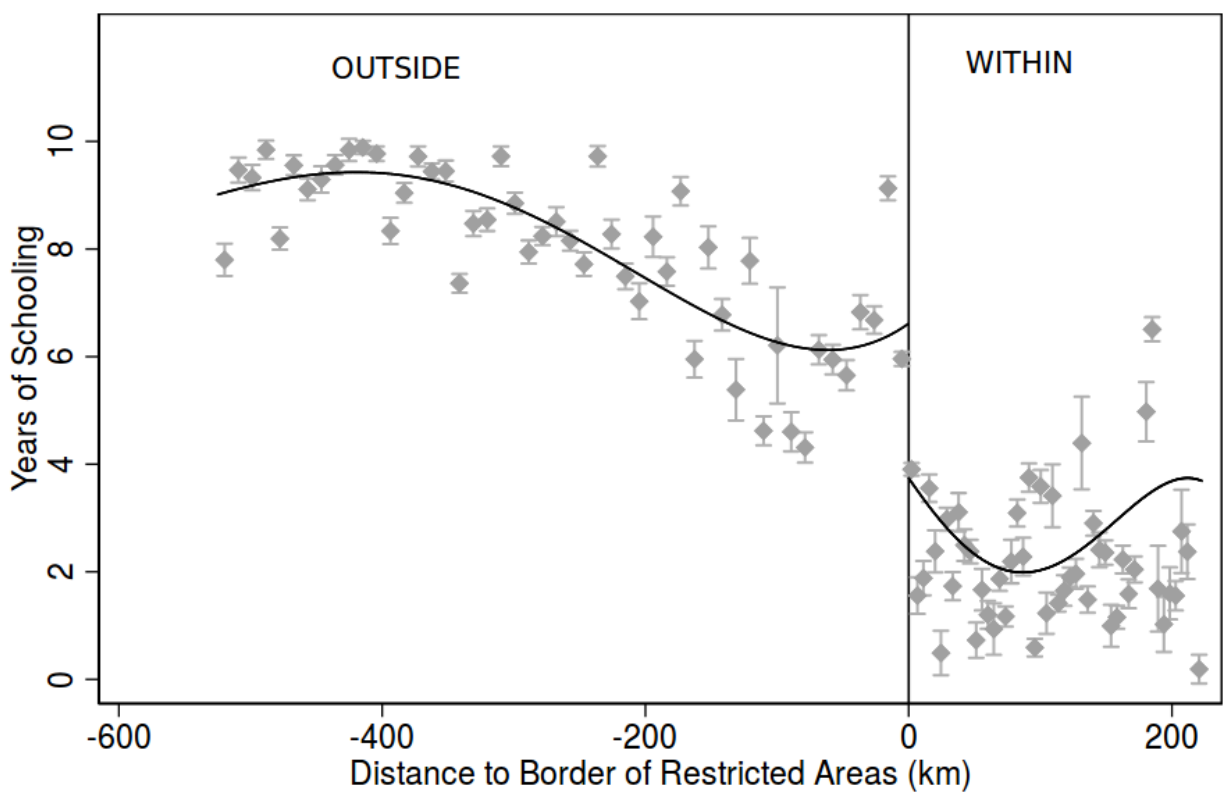

Sample average within bin

Polynomial fit of order 4

Note: Points show binned means using 50 bins. Standard errors clustered at the local government area level, and bars show 95\% confidence intervals. Regression line is estimated using fourth-order polynomials of distance to border of restricted area. Negative distance indicates areas outside the restricted areas and positive distance indicates restricted areas. 
Figure 4: Differences in Probability of Colonial Infrastructure 10km Inside and Outside Restricted Provinces

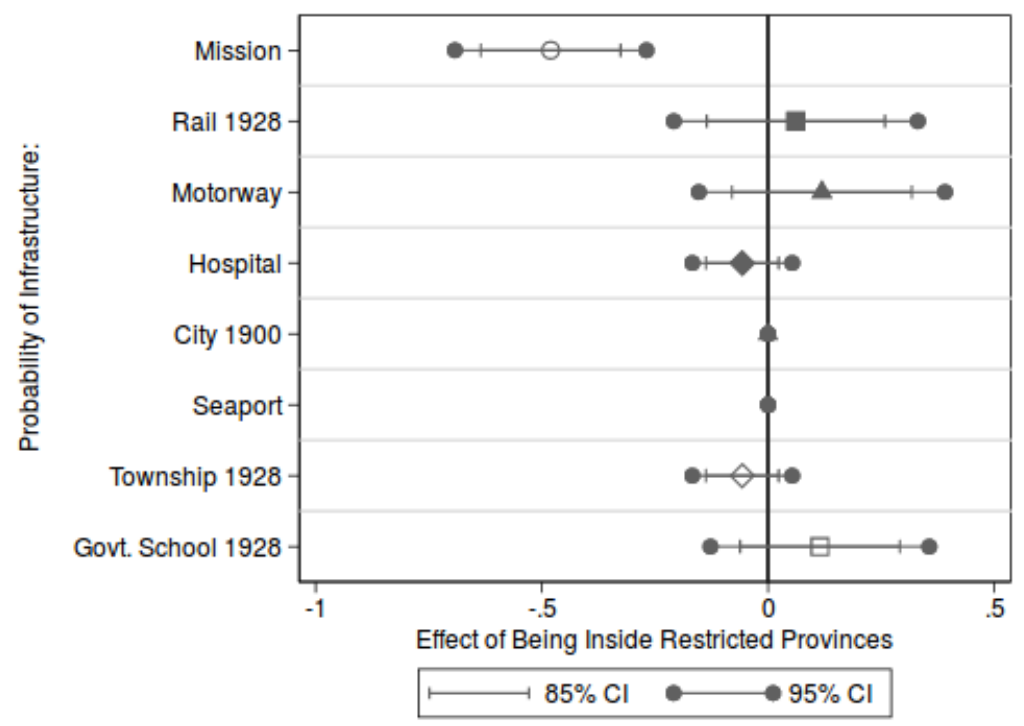

Note: Standard errors clustered at the local government area level. For local areas within $10 \mathrm{~km}$ of the border of the Restricted Provinces, Figure shows estimated probability of infrastructure presence in the early 20th century for areas within the provinces relative to areas just outside the provinces. Effects computed from Table 2.

Figure 5: Heterogeneity by Initial Supply and Demand Conditions

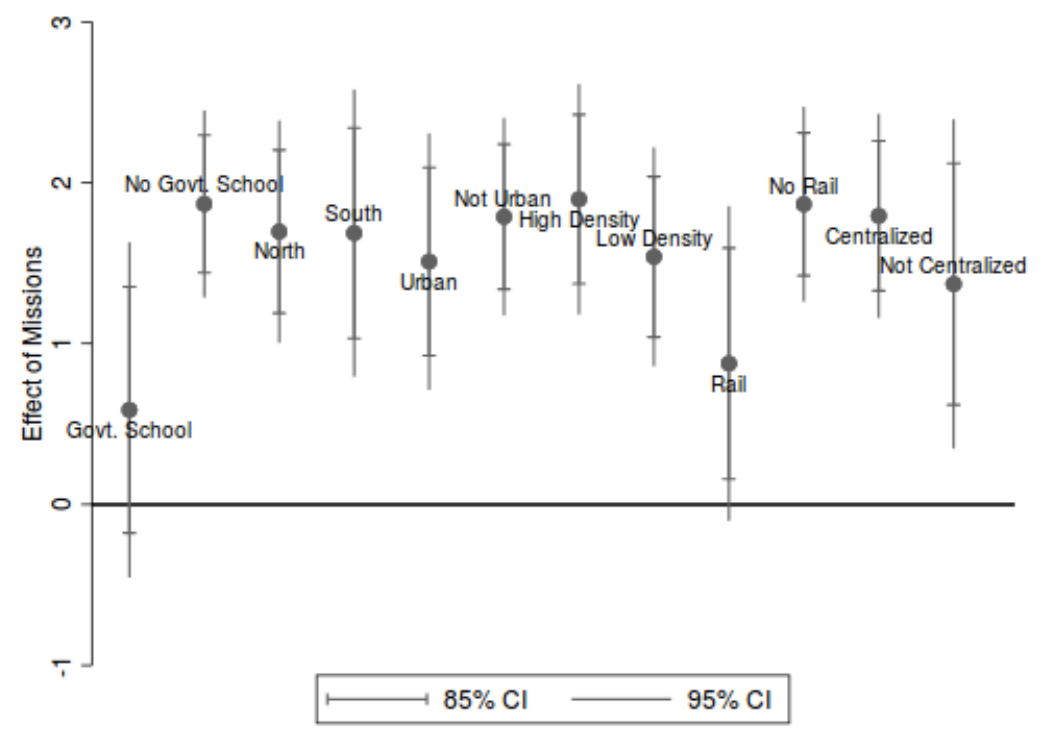

Note: Standard errors clustered at the local government area level. Figure shows estimates of the effects of historical missionary activity on schooling attainment in Nigeria. Heterogeneous effects are computed from Table 5. 
Table 1: Summary Statistics

\begin{tabular}{|c|c|c|}
\hline & Mean & $\mathrm{SD}$ \\
\hline & \multicolumn{2}{|c|}{ Primary Missions } \\
\hline Mission in LGA & .2 & .4 \\
\hline Within $20 \mathrm{~km}$ & .61 & .49 \\
\hline Between 20 and $40 \mathrm{~km}$ & .1 & .3 \\
\hline Between 40 and $60 \mathrm{~km}$ & .06 & .24 \\
\hline Between 60 and $80 \mathrm{~km}$ & .03 & .17 \\
\hline \multirow[t]{2}{*}{ Above $80 \mathrm{~km}$} & .2 & .4 \\
\hline & \multicolumn{2}{|c|}{ Location and Colonial Investments in Local Area } \\
\hline Northern Nigeria & .57 & .49 \\
\hline Rail in LGA & .22 & .41 \\
\hline Expressway in LGA & .38 & .48 \\
\hline Presence of Hospitals in 1928 & .03 & .18 \\
\hline City in 1900 & .05 & .21 \\
\hline Major seaport in LGA & .01 & .11 \\
\hline Township in 1928 & .04 & .2 \\
\hline \multirow[t]{2}{*}{ Government school in 1928} & .21 & .48 \\
\hline & \multicolumn{2}{|c|}{ Initial Population Conditions of Local Area } \\
\hline Urbanization Rate in 1900 & .13 & .23 \\
\hline 1900 Total Population & 40635.52 & 30655.23 \\
\hline \multirow[t]{2}{*}{1900 Pop Density } & 115.03 & 280.45 \\
\hline & \multicolumn{2}{|c|}{ Geographic and Agricultural Conditions } \\
\hline Distance to Coast & 334.82 & 290.59 \\
\hline Major River in LGA & .51 & .5 \\
\hline Total area of LGA & 1375.5 & 1674.1 \\
\hline Malaria Ecology & .59 & .12 \\
\hline Distance to border & 122.97 & 93.59 \\
\hline Mean cocoa suitability & .55 & .56 \\
\hline Mean cotton suitability & .54 & .23 \\
\hline Mean groundnut suitability & 1.95 & .38 \\
\hline Combined land suitability & 4.1 & .68 \\
\hline Mean oil palm suitability & 2.05 & 2.16 \\
\hline Mean Precipitation in LGA & 1345.07 & 591.58 \\
\hline Mean Elevation in LGA & 288.91 & 228.31 \\
\hline \multirow[t]{2}{*}{ Ruggedness Index in LGA } & 45.48 & 42.14 \\
\hline & \multicolumn{2}{|c|}{ Ethnic Heritage of Local Area } \\
\hline Ethnic Majority LGA & .94 & .23 \\
\hline Intensity of Agriculture & 3.58 & .91 \\
\hline Settlement Patterns & 6.7 & .95 \\
\hline Within Hierarchy & 3.47 & .58 \\
\hline Centralized Ethnic Group & .52 & .5 \\
\hline Class Stratification & .87 & .33 \\
\hline Monogamous & 0 & \\
\hline Marital Composition & 5.1 & .76 \\
\hline Female Bias in Agric & .15 & .35 \\
\hline Bride Price & .98 & .16 \\
\hline Number of Observations & 123310 & 123310 \\
\hline Number of DHS Clusters & 2430 & 2430 \\
\hline Number of Local Government Areas & 713 & 713 \\
\hline
\end{tabular}

Note: Table shows summary statistics of variables at the local government area (LGA) level as used in the empirical estimation. Variables are constructed as described in the text. Distances are measured in kilometres. 


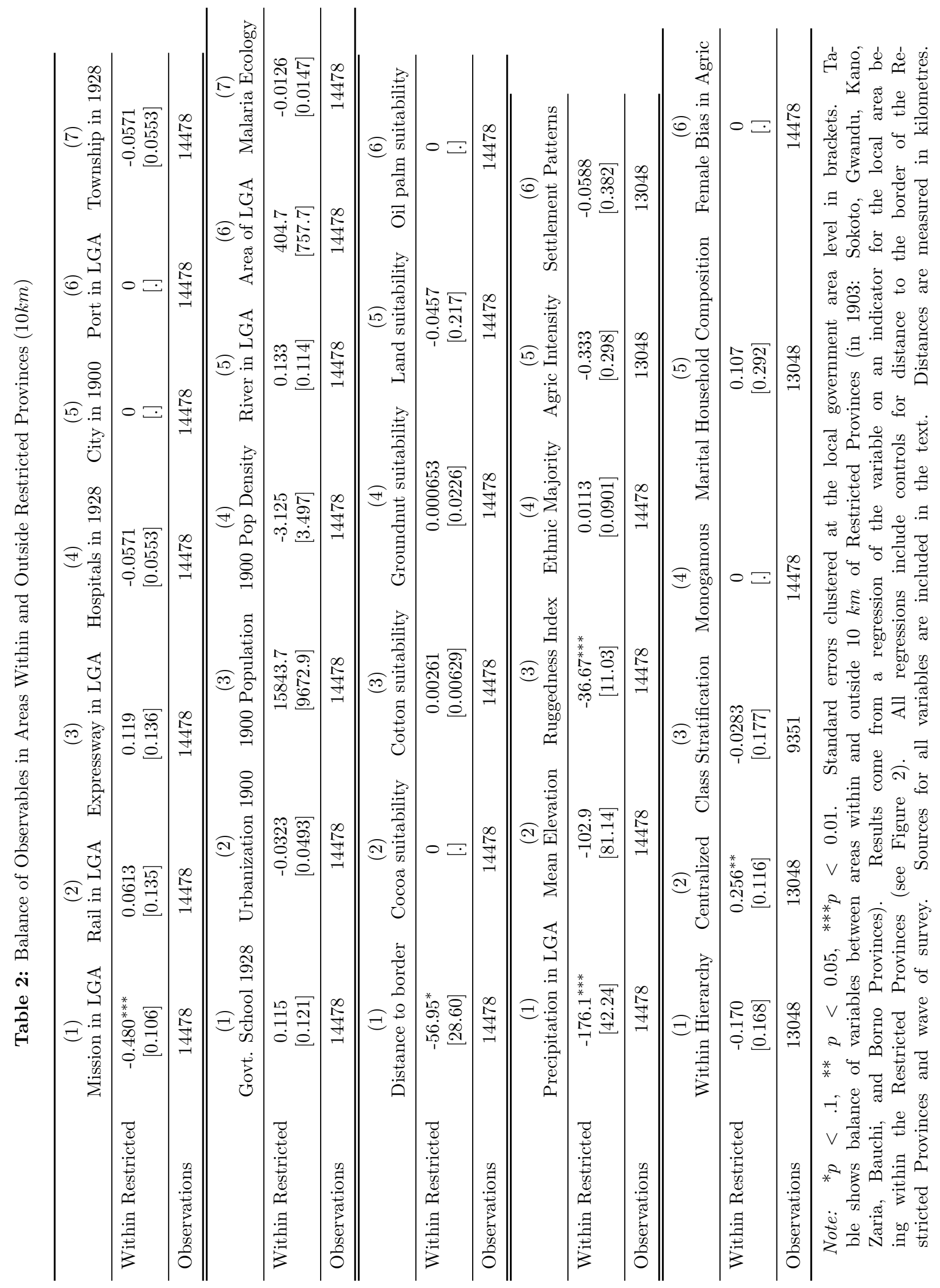


Table 3: Long-Run Effects of Missions on Schooling Attainment

\begin{tabular}{|c|c|c|c|c|c|c|}
\hline & $\begin{array}{c}(1) \\
\text { Schooling }\end{array}$ & $\begin{array}{c}(2) \\
\text { Schooling }\end{array}$ & $\begin{array}{c}(3) \\
\text { Schooling }\end{array}$ & $\begin{array}{c}(4) \\
\text { Schooling }\end{array}$ & $\begin{array}{c}(5) \\
\text { Schooling }\end{array}$ & $\begin{array}{c}(6) \\
\text { Schooling }\end{array}$ \\
\hline Within $20 \mathrm{~km} \times$ Mission in LGA $=0$ & $\begin{array}{c}6.251^{* * *} \\
{[0.273]}\end{array}$ & & & & & \\
\hline Within $20 \mathrm{~km} \times$ Mission in LGA $=1$ & $\begin{array}{c}6.199^{* * *} \\
{[0.287]}\end{array}$ & & & & & \\
\hline Within $20 \mathrm{~km}$ & $\begin{array}{c}0 \\
{[.]}\end{array}$ & $\begin{array}{c}4.461^{* * *} \\
{[0.328]}\end{array}$ & $\begin{array}{c}2.655^{* * *} \\
{[0.412]}\end{array}$ & $\begin{array}{c}2.556^{* * *} \\
{[0.414]}\end{array}$ & $\begin{array}{c}2.272^{* * *} \\
{[0.340]}\end{array}$ & $\begin{array}{c}2.183^{* * *} \\
{[0.345]}\end{array}$ \\
\hline Between 20 and $40 \mathrm{~km}$ & $\begin{array}{c}3.983^{* * *} \\
{[0.450]}\end{array}$ & $\begin{array}{c}2.813^{* * *} \\
{[0.397]}\end{array}$ & $\begin{array}{c}1.351^{* * *} \\
{[0.447]}\end{array}$ & $\begin{array}{c}1.290^{* * *} \\
{[0.444]}\end{array}$ & $\begin{array}{c}1.344^{* * *} \\
{[0.375]}\end{array}$ & $\begin{array}{c}1.294^{* * *} \\
{[0.379]}\end{array}$ \\
\hline Between 40 and $60 \mathrm{~km}$ & $\begin{array}{c}2.545^{* * *} \\
{[0.548]}\end{array}$ & $\begin{array}{c}1.563^{* * *} \\
{[0.394]}\end{array}$ & $\begin{array}{c}0.333 \\
{[0.432]}\end{array}$ & $\begin{array}{c}0.486 \\
{[0.406]}\end{array}$ & $\begin{array}{c}0.425 \\
{[0.374]}\end{array}$ & $\begin{array}{l}0.809^{* *} \\
{[0.391]}\end{array}$ \\
\hline Between 60 and $80 \mathrm{~km}$ & $\begin{array}{c}0.613 \\
{[0.397]}\end{array}$ & $\begin{array}{c}0.606 \\
{[0.399]}\end{array}$ & $\begin{array}{c}0.188 \\
{[0.441]}\end{array}$ & $\begin{array}{c}0.195 \\
{[0.410]}\end{array}$ & $\begin{array}{c}0.479 \\
{[0.375]}\end{array}$ & $\begin{array}{c}0.651 \\
{[0.435]}\end{array}$ \\
\hline Northern Nigeria & & $\begin{array}{c}-2.967^{* * *} \\
{[0.274]}\end{array}$ & $\begin{array}{l}-0.439 \\
{[0.390]}\end{array}$ & $\begin{array}{l}-0.724^{*} \\
{[0.414]}\end{array}$ & $\begin{array}{l}-0.784^{*} \\
{[0.405]}\end{array}$ & $\begin{array}{c}-0.0477 \\
{[0.504]}\end{array}$ \\
\hline Distance to Coast & & & $\begin{array}{c}0.00113 \\
{[0.00165]}\end{array}$ & $\begin{array}{c}0.00143 \\
{[0.00152]}\end{array}$ & $\begin{array}{c}0.00106 \\
{[0.00131]}\end{array}$ & $\begin{array}{c}0.00281^{* *} \\
{[0.00141]}\end{array}$ \\
\hline Mean Schooling & 6.346 & 6.346 & 6.346 & 6.346 & 6.346 & 6.389 \\
\hline North Fixed Effect & No & Yes & Yes & Yes & Yes & Yes \\
\hline Geographic Controls & No & No & Yes & Yes & Yes & Yes \\
\hline Colonial Investments & No & No & No & Yes & Yes & Yes \\
\hline Population Conditions & No & No & No & No & Yes & Yes \\
\hline Ethnic Heritage & No & No & No & No & No & Yes \\
\hline Adjusted $\mathrm{R}^{2}$ & 0.249 & 0.304 & 0.337 & 0.345 & 0.361 & 0.384 \\
\hline Number of LGA's & 713 & 713 & 713 & 713 & 713 & 600 \\
\hline Observations & 123207 & 123207 & 123207 & 123207 & 123207 & 100695 \\
\hline
\end{tabular}

Note: ${ }^{*} p<.1,{ }^{* *} p<0.05,{ }^{* * *} p<0.01$. Standard errors clustered at the local government area level in brackets. Table shows estimated effects of historical missionary activity on schooling attainment in Nigeria, using data from the 1990, 2003, 2008, and 2013, Demographic and Health Surveys. Areas in the excluded category are local areas beyond $80 \mathrm{~km}$ of a primary station in 1928 . North fixed effect refers to the states of historical Northern Nigeria. Geographic controls include controls for a number of geographic and agricultural characteristics and include distance to coast, presence of a major river, total area of the LGA, malaria ecology of the LGA, distance to the nearest border, suitability for primary export crops in the colonial era (cocoa, cotton, groundnuts, and oil palm), mean precipitation, elevation, and ruggedness. Colonial investments refer to controls for major colonial-era investments and include presence of the railway line, presence of a major motorway, presence of a hospital, city presence in 1900 , presence of a major seaport, township presence in 1928, and presence of a government school in 1928 . Population conditions refer to urbanization rate of local area in 1900, total population of local area in 1900, and 1900 population density of local area. Ethnic heritage controls include an indicator for whether there is an ethnic majority in the local area, and measures for the intensity of agriculture, settlement patterns, political hierarchy, centralization, class stratification, marital living composition, female bias in agriculture, and bride price payments, for the majority historical ethnic group in the local area. All regressions include indicators for wave of survey, and variables are constructed as described in the text. 
Table 4: Fuzzy RD: Effects of Missions on Schooling at Different Bandwidths

Panel A: Second-Stage Estimates, Dependent Variable is Years of Schooling

\begin{tabular}{|c|c|c|c|c|c|c|}
\hline \multirow{3}{*}{ Bandwith Around Border: } & \multirow{2}{*}{\multicolumn{2}{|c|}{$\begin{array}{l}(1) \\
\text { Within } 10 \mathrm{~km}\end{array}$}} & (3) & $(4)$ & (5) & (6) \\
\hline & & & \multicolumn{2}{|c|}{ Within $20 \mathrm{~km}$} & \multicolumn{2}{|c|}{ Within $30 \mathrm{~km}$} \\
\hline & No Controls & Controls & No Controls & Controls & No Controls & Controls \\
\hline \multirow[t]{2}{*}{ Mission in LGA } & $4.639^{* * *}$ & $2.923^{*}$ & $7.650^{* * *}$ & $3.432^{* *}$ & $9.057^{* *}$ & $3.761^{* *}$ \\
\hline & {$[1.619]$} & {$[1.550]$} & {$[2.700]$} & {$[1.530]$} & {$[3.595]$} & {$[1.617]$} \\
\hline Mean Schooling & 4.672 & 4.672 & 5.104 & 5.104 & 4.964 & 4.964 \\
\hline Observations & 14457 & 9335 & 18211 & 10821 & 22302 & 13368 \\
\hline Number of LGA's & 70.00 & 47.00 & 86.00 & 57.00 & 103.00 & 68.00 \\
\hline Centered R-sq. & 0.06 & 0.24 & -0.04 & 0.22 & -0.15 & 0.21 \\
\hline Kleibergen-Paap UnderId & 12.61 & 8.39 & 13.63 & 7.90 & 14.44 & 7.00 \\
\hline Kleibergen-Paap F (Weak Id) & 20.51 & 10.92 & 18.77 & 10.03 & 15.86 & 9.53 \\
\hline
\end{tabular}

Panel B: First Stage Estimates, Dependent Variable is Mission in Local Area

\begin{tabular}{|c|c|c|c|c|c|c|}
\hline \multirow{3}{*}{ Bandwith Around Border: } & \multirow{2}{*}{\multicolumn{2}{|c|}{$\begin{array}{l}(1) \\
\text { Within } 10 \mathrm{~km}\end{array}$}} & (3) & $(4)$ & (5) & $(6)$ \\
\hline & & & \multicolumn{2}{|c|}{ Within $20 \mathrm{~km}$} & \multicolumn{2}{|c|}{ Within $30 \mathrm{~km}$} \\
\hline & No Controls & Controls & No Controls & Controls & No Controls & Controls \\
\hline Within Restricted Provinces & $\begin{array}{c}-0.480^{* * *} \\
{[0.106]}\end{array}$ & $\begin{array}{c}-0.417^{* * *} \\
{[0.126]}\end{array}$ & $\begin{array}{c}-0.400^{* * *} \\
{[0.092]}\end{array}$ & $\begin{array}{c}-0.399^{* * *} \\
{[0.126]}\end{array}$ & $\begin{array}{c}-0.368^{* * *} \\
{[0.093]}\end{array}$ & $\begin{array}{c}-0.400^{* * *} \\
{[0.129]}\end{array}$ \\
\hline Observations & 14457 & 9335 & 18211 & 10821 & 22302 & 13368 \\
\hline Geographic Controls & No & Yes & No & Yes & No & Yes \\
\hline Colonial Investments & No & Yes & No & Yes & No & Yes \\
\hline Population Conditions & No & Yes & No & Yes & No & Yes \\
\hline Ethnic Heritage & No & Yes & No & Yes & No & Yes \\
\hline
\end{tabular}

Note: ${ }^{*} p<.1,{ }^{* *} p<0.05,{ }^{* * *} p<0.01$. Standard errors clustered at the local government area level in brackets. Table shows two-stage least squares estimates of the effects of historical missionary activity on schooling attainment in Nigeria, using data from the 1990, 2003, 2008, and 2013, Demographic and Health Surveys. The sample is restricted to local areas within 10, 20, and $30 \mathrm{~km}$ of the Restricted Provinces (in 1903: Sokoto, Gwandu, Kano, Zaria, Bauchi, and Borno Provinces), and the instrument is an indicator for being within the Provinces. The Table also shows test statistics from the Kleibergen and Paap (2006) LM-test of under-identification (Kleibergen-Paap UnderId) and the Kleibergen and Paap (2006) F-test of weak identification (Kleibergen-Paap F). All regressions control for distance to border of the Restricted Provinces. Additional controls refer to variables that vary between local areas. Geographic controls include controls for a number of geographic and agricultural characteristics: presence of a major river, total area of the LGA, malaria ecology of the LGA, distance to the nearest border, suitability for primary export crops in the colonial era in the region (cotton, groundnuts), mean precipitation, elevation, and ruggedness. Colonial investments refer to controls for major colonial-era investments in the region and include presence of the railway line, presence of a major motorway, presence of a hospital, township presence in 1928, and presence of a government school in 1928. Population conditions refer to urbanization rate of local area in 1900, total population of local area in 1900, and 1900 population density of local area. Ethnic heritage controls include an indicator for whether there is an ethnic majority in the local area, and measures for the intensity of agriculture, settlement patterns, political hierarchy, centralization, class stratification, and marital living composition for the majority historical ethnic group in the local area. All regressions include indicators for wave of survey, and variables are constructed as described in the text. 
Table 5: Heterogeneous Effects of Missions by Proxies for Initial Conditions

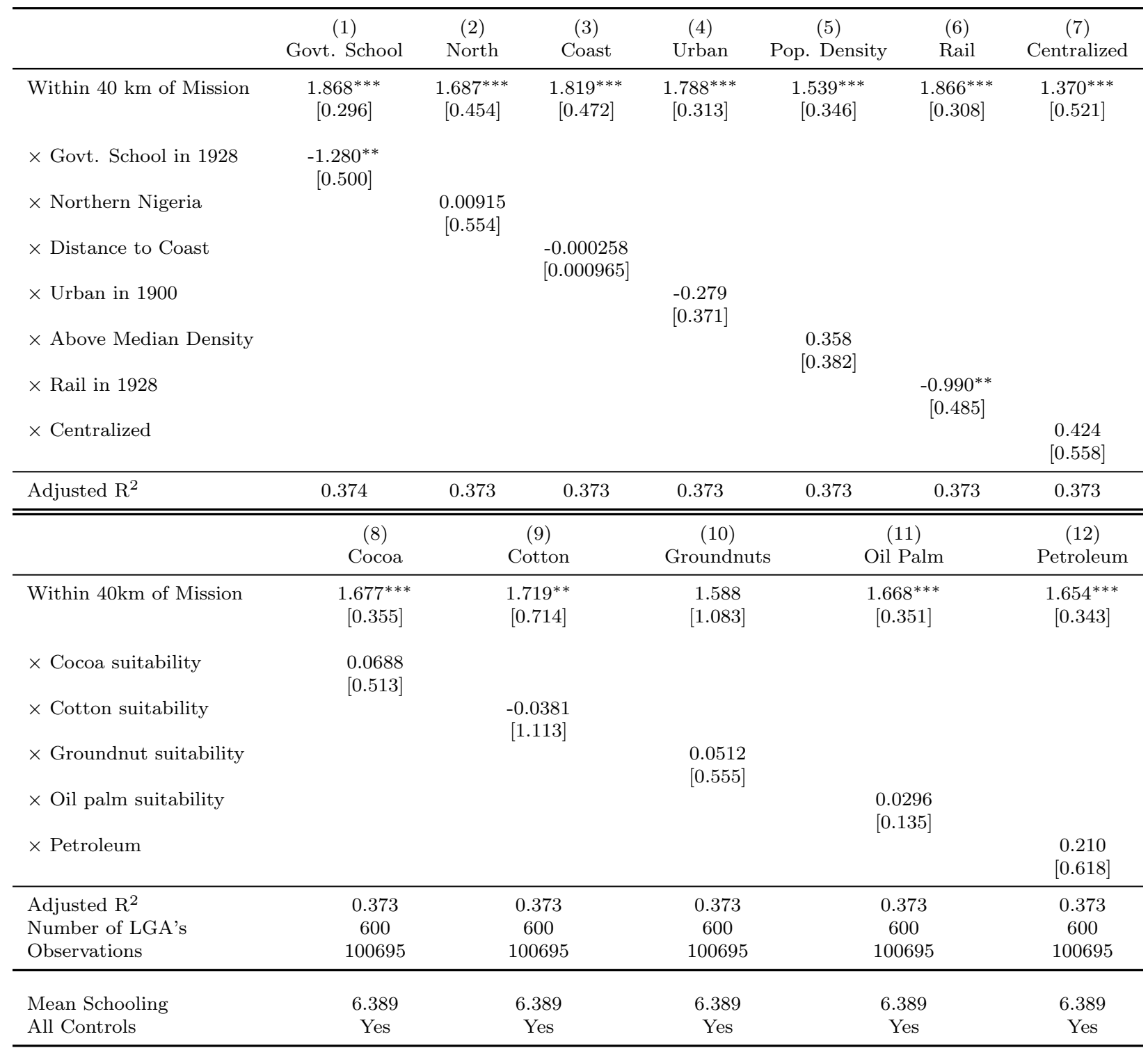

Note: ${ }^{*} p<.1,{ }^{* *} p<0.05,{ }^{* * *} p<0.01$. Standard errors clustered at the local government area level in brackets. Table shows estimates of the effects of historical missionary activity on schooling attainment in Nigeria, using data from the 1990, 2003, 2008, and 2013, Demographic and Health Surveys. The Tables show heterogeneous effects by proxies for initial supply (government schools, rail) and other demand conditions. Areas in the excluded category are local areas beyond $40 \mathrm{~km}$ of 1928 primary mission stations. All controls include: North fixed effect refers to the states of historical Northern Nigeria. Geographic controls include controls for a number of geographic and agricultural characteristics and include distance to coast, presence of a major river, total area of the LGA, malaria ecology of the LGA, distance to the nearest border, suitability for primary export crops in the colonial era (cocoa, cotton, groundnuts, and oil palm), mean precipitation, elevation, and ruggedness. Colonial investments refer to controls for major colonial-era investments and include presence of the railway line, presence of a major motorway, presence of a hospital, city presence in 1900, presence of a major seaport, township presence in 1928, and presence of a government school in 1928. Population conditions refer to urbanization rate of local area in 1900, total population of local area in 1900, and 1900 population density of local area. Ethnic heritage controls include an indicator for whether there is an ethnic majority in the local area, and measures for the intensity of agriculture, settlement patterns, political hierarchy, centralization, class stratification, marital living composition, female bias in agriculture, and bride price payments, for the majority historical ethnic group in the local area. All regressions include indicators for wave of survey, and variables are constructed as described in the text. 
Table 6: Effects of Missions on Schooling Attainment by Individual Characteristics

\begin{tabular}{lcccc}
\hline & $(1)$ & $(2)$ & $(3)$ & $(4)$ \\
& Sex & Religion & Christian & Muslim \\
\hline Within 40 km of Mission & $1.691^{* * *}$ & $1.643^{* * *}$ & $1.016^{* *}$ & $0.958^{* * *}$ \\
& {$[0.266]$} & {$[0.277]$} & {$[0.490]$} & {$[0.271]$} \\
$\times$ Male & $-0.749^{* * *}$ & & $-1.077^{* * *}$ & 0.163 \\
& {$[0.148]$} & & {$[0.325]$} & {$[0.197]$} \\
$\times$ Christian & & & & \\
& & $-1.056^{* *}$ & & \\
\hline Adjusted R & {$[0.463]$} & 0.187 & 0.351 \\
Number of LGA's & 0.406 & 0.402 & 492 & 504 \\
Observations & 600 & 600 & 51231 & 43787 \\
\hline & 100695 & 95514 & 8.943 & 3.803 \\
Mean Schooling & & & Yes & Yes \\
North Fixed Effect & 6.389 & 6.573 & Yes & Yes \\
Geographic Controls & Yes & Yes & Yes & Yes \\
Colonial Investments & Yes & Yes & Yes & Yes \\
Population Conditions & Yes & Yes & Yes & Yes \\
Ethnic Heritage & Yes & Yes &
\end{tabular}

Note: ${ }^{*} p<.1,{ }^{* *} p<0.05,{ }^{* * *} p<0.01$. Standard errors clustered at the local government area level in brackets. Table shows estimated effects of historical missionary activity on schooling attainment in Nigeria, using data from the 1990, 2003, 2008, and 2013, Demographic and Health Surveys. Heterogeneous effects by individual characteristics are shown. Areas in the excluded category are local areas beyond $40 \mathrm{~km}$ of a primary station in 1928. North fixed effect refers to the states of historical Northern Nigeria. Geographic controls include controls for a number of geographic and agricultural characteristics and include distance to coast, presence of a major river, total area of the LGA, malaria ecology of the LGA, distance to the nearest border, suitability for primary export crops in the colonial era (cocoa, cotton, groundnuts, and oil palm), mean precipitation, elevation, and ruggedness. Colonial investments refer to controls for major colonial-era investments and include presence of the railway line, presence of a major motorway, presence of a hospital, city presence in 1900, presence of a major seaport, township presence in 1928, and presence of a government school in 1928. Population conditions refer to urbanization rate of local area in 1900, total population of local area in 1900, and 1900 population density of local area. Ethnic heritage controls include an indicator for whether there is an ethnic majority in the local area, and measures for the intensity of agriculture, settlement patterns, political hierarchy, centralization, class stratification, marital living composition, female bias in agriculture, and bride price payments, for the majority historical ethnic group in the local area. All regressions include indicators for wave of survey, and variables are constructed as described in the text. 
Table 7: Effects of Missions on Fertility Decisions

\begin{tabular}{lccc}
\hline & $(1)$ & $(2)$ & $(3)$ \\
& Total Children & Living Children & Ideal Children \\
\hline Within $20 \mathrm{~km}$ & $-0.394^{* * *}$ & $-0.250^{* * *}$ & $-0.908^{* * *}$ \\
& {$[0.0737]$} & {$[0.0575]$} & {$[0.180]$} \\
Between 20 and 40km & $-0.283^{* * *}$ & $-0.191^{* * *}$ & $-0.357^{*}$ \\
& {$[0.0765]$} & {$[0.0601]$} & {$[0.208]$} \\
Between 40 and 60km & $-0.199^{*}$ & -0.0928 & -0.0189 \\
& {$[0.102]$} & {$[0.0714]$} & {$[0.243]$} \\
\hline Mean Outcome & 2.867 & 2.337 & 6.681 \\
North Fixed Effect & Yes & Yes & Yes \\
Geographic Controls & Yes & Yes & Yes \\
Colonial Investments & Yes & Yes & Yes \\
Population Conditions & Yes & Yes & Yes \\
Ethnic Heritage & Yes & 0.536 & 0.251 \\
Adjusted R & 0.569 & 600 & 600 \\
Number of LGA's & 600 & 99209 & 86769 \\
Observations & 99209 & & \\
\hline
\end{tabular}

Note: ${ }^{*} p<.1,{ }^{* *} p<0.05,{ }^{* * *} p<0.01$. Standard errors clustered at the local government area level in brackets. Table shows estimated effects of historical missionary activity on the fertility decisions of women in Nigeria, using data from the 1990, 2003, 2008, and 2013, Demographic and Health Surveys. Heterogeneous effects by individual characteristics are shown. Areas in the excluded category are local areas beyond $80 \mathrm{~km}$ of a primary station in 1928. North fixed effect refers to the states of historical Northern Nigeria. Geographic controls include controls for a number of geographic and agricultural characteristics and include distance to coast, presence of a major river, total area of the LGA, malaria ecology of the LGA, distance to the nearest border, suitability for primary export crops in the colonial era (cocoa, cotton, groundnuts, and oil palm), mean precipitation, elevation, and ruggedness. Colonial investments refer to controls for major colonial-era investments and include presence of the railway line, presence of a major motorway, presence of a hospital, city presence in 1900, presence of a major seaport, township presence in 1928, and presence of a government school in 1928. Population conditions refer to urbanization rate of local area in 1900, total population of local area in 1900, and 1900 population density of local area. Ethnic heritage controls include an indicator for whether there is an ethnic majority in the local area, and measures for the intensity of agriculture, settlement patterns, political hierarchy, centralization, class stratification, marital living composition, female bias in agriculture, and bride price payments, for the majority historical ethnic group in the local area. All regressions include indicators for wave of survey, age group of respondent, and variables are constructed as described in the text. 
Table 8: Initial and Current Development of Areas Within and Outside Restricted Provinces

\begin{tabular}{|c|c|c|c|c|c|c|c|c|}
\hline & \multicolumn{2}{|c|}{ Past } & \multicolumn{6}{|c|}{ Present } \\
\hline & $\begin{array}{c}(1) \\
\text { Centralized }\end{array}$ & $\begin{array}{c}(2) \\
\text { Density }\end{array}$ & $\begin{array}{c}(3) \\
\text { Schooling }\end{array}$ & $\begin{array}{l}\text { All Area } \\
\quad(4) \\
\text { Wealth }\end{array}$ & $\begin{array}{l}(5) \\
\text { Wealth Score }\end{array}$ & $\begin{array}{c}(6) \\
\text { Schooling }\end{array}$ & $\begin{array}{c}\text { Northern } A \\
\quad(7) \\
\text { Wealth }\end{array}$ & $\begin{array}{l}\text { (8) } \\
\text { Wealth Score }\end{array}$ \\
\hline Within Restricted Provinces & $\begin{array}{l}0.151^{* *} \\
{[0.0598]}\end{array}$ & $\begin{array}{l}100.1^{* * *} \\
{[35.45]}\end{array}$ & $\begin{array}{l}-1.319^{* * *} \\
{[0.478]}\end{array}$ & $\begin{array}{l}-0.0689 \\
{[0.163]}\end{array}$ & $\begin{array}{l}-5064.7 \\
{[10891.0]}\end{array}$ & $\begin{array}{l}-1.555^{* * *} \\
{[0.511]}\end{array}$ & $\begin{array}{l}-0.383^{* *} \\
{[0.150]}\end{array}$ & $\begin{array}{l}-26189.2^{\text {*** }} \\
{[9725.7]}\end{array}$ \\
\hline Mean Schooling & 0.552 & 101.9 & 6.389 & 3.074 & 1326.1 & 3.946 & 2.431 & $-4.35 e+04$ \\
\hline North Fixed Effect & Yes & Yes & Yes & Yes & Yes & No & No & No \\
\hline Geographic Controls & Yes & Yes & Yes & Yes & Yes & Yes & Yes & Yes \\
\hline Colonial Investments & No & No & No & No & No & No & No & No \\
\hline Population Conditions & Yes & Yes & Yes & Yes & Yes & Yes & Yes & Yes \\
\hline Ethnic Heritage & Yes & Yes & Yes & Yes & Yes & Yes & Yes & Yes \\
\hline Adjusted $\mathrm{R}^{2}$ & 0.814 & 0.446 & 0.368 & 0.414 & 0.410 & 0.232 & 0.318 & 0.332 \\
\hline Number of LGA's & 600 & 600 & 600 & 596 & 596 & 296 & 294 & 294 \\
\hline Observations & 100781 & 100781 & 100695 & 93912 & 93912 & 52319 & 49642 & 49642 \\
\hline
\end{tabular}

Note: ${ }^{*} p<.1,{ }^{* *} p<0.05,{ }^{* * *} p<0.01$. Standard errors clustered at the local government area level in brackets. Table shows estimates of the relationship between living within the restricted provinces and local development using different proxies in the past and present. Regressions using household wealth measures control for household size. North fixed effect refers to the states of historical Northern Nigeria. Geographic controls include controls for a number of geographic and agricultural characteristics and include distance to coast, presence of a major river, total area of the LGA, malaria ecology of the LGA, distance to the nearest border, suitability for primary export crops in the colonial era (cocoa, cotton, groundnuts, and oil palm), mean precipitation, elevation, and ruggedness. Colonial investments refer to controls for major colonial-era investments and include presence of the railway line, presence of a major motorway, presence of a hospital, city presence in 1900, presence of a major seaport, township presence in 1928, and presence of a government school in 1928. Population conditions refer to total population of local area in 1900. Ethnic heritage controls include an indicator for whether there is an ethnic majority in the local area, and measures for the intensity of agriculture, settlement patterns, political hierarchy, class stratification, marital living composition, female bias in agriculture, and bride price payments, for the majority historical ethnic group in the local area. All regressions include indicators for wave of survey, and variables are constructed as described in the text. 
Table 9: Mediation: Missions and Current Development of Areas Within and Outside Restricted Provinces

\begin{tabular}{lccc|ccc} 
& \multicolumn{3}{c}{ All Areas } & \multicolumn{3}{c}{ Northern Areas } \\
\hline & $(1)$ & $(2)$ & $(3)$ & $(4)$ & $(5)$ & $(6)$ \\
& Schooling & Wealth & Wealth Score & Schooling & Wealth & Wealth Score \\
\hline Within Restricted Provinces & -0.339 & 0.242 & 17416.2 & $-0.903^{*}$ & -0.179 & -13272.6 \\
& {$[0.475]$} & {$[0.186]$} & {$[12589.7]$} & {$[0.481]$} & {$[0.165]$} & {$[10810.1]$} \\
Within 40 km & $1.970^{* * *}$ & $0.545^{* * *}$ & $38692.5^{* * *}$ & $1.854^{* * *}$ & $0.522^{* * *}$ & $34183.3^{* * *}$ \\
& {$[0.342]$} & {$[0.142]$} & {$[9841.4]$} & {$[0.386]$} & {$[0.160]$} & {$[10823.2]$} \\
\hline Mean Outcome & 6.389 & 3.074 & 1326.066 & 3.946 & 2.431 & $-4.35 \mathrm{e}+04$ \\
North Fixed Effect & Yes & Yes & Yes & No & No & No \\
Geographic Controls & Yes & Yes & Yes & Yes & Yes & Yes \\
Population Conditions & Yes & Yes & Yes & Yes & Yes & Yes \\
Ethnic Heritage & Yes & Yes & Yes & Yes & Yes & Yes \\
Adjusted R & 0.360 & 0.355 & 0.339 & 0.220 & 0.228 & 0.229 \\
Number of LGA's & 600 & 596 & 596 & 296 & 294 & 294 \\
Observations & 100695 & 93912 & 93912 & 52319 & 49642 & 49642 \\
\hline
\end{tabular}

Note: ${ }^{*} p<.1,{ }^{* *} p<0.05,{ }^{* * *} p<0.01$. Standard errors clustered at the local government area level in brackets. Table shows estimates of the relationship between living within the restricted provinces and local development today, accounting for missionary activities. Regressions using household wealth measures control for household size. North fixed effect refers to the states of historical Northern Nigeria. Geographic controls include controls for a number of geographic and agricultural characteristics and include distance to coast, presence of a major river, total area of the LGA, malaria ecology of the LGA, distance to the nearest border, suitability for primary export crops in the colonial era (cocoa, cotton, groundnuts, and oil palm), mean precipitation, elevation, and ruggedness. Colonial investments refer to controls for major colonial-era investments and include presence of the railway line, presence of a major motorway, presence of a hospital, city presence in 1900, presence of a major seaport, township presence in 1928, and presence of a government school in 1928. Population conditions refer to total population of local area in 1900. Ethnic heritage controls include an indicator for whether there is an ethnic majority in the local area, and measures for the intensity of agriculture, settlement patterns, political hierarchy, class stratification, marital living composition, female bias in agriculture, and bride price payments, for the majority historical ethnic group in the local area. All regressions include indicators for wave of survey, and variables are constructed as described in the text. 


\section{References}

Abdurrahman, Umar, "Religion and language in the transformation of education in northern Nigeria during British colonial rule, 1900-1960," Intellectual Discourse, 2012, 20 (2).

Acemoglu, Daron, Simon Johnson, and James A Robinson, "The colonial origins of comparative development: An empirical investigation," American economic review, 2001, 91 (5), 1369-1401.

$\ldots, \ldots$, and _ , "Reversal of fortune: Geography and institutions in the making of the modern world income distribution," The Quarterly journal of economics, 2002, 117 (4), 1231-1294.

_, _, and James A. Robinson, "Reversal Of Fortune: Geography And Institutions In The Making Of The Modern World Income Distribution," The Quarterly Journal of Economics, November 2002, 117 (4), $1231-1294$.

_, Tristan Reed, and James A Robinson, "Chiefs: Economic development and elite control of civil society in Sierra Leone," Journal of Political Economy, 2014, 122 (2), 319-368.

Adebayo, A. G., "Jangali: Fulani Pastoralists and Colonial Taxation in Northern Nigeria," The International Journal of African Historical Studies, 1995, 28 (1), 113-150.

Afigbo, A. E., The Warrant Chiefs: Indirect Rule in Southeastern Nigeria, 1891-1929 Ibadan History Series, New York: Humanities Press, 1972.

Ajayi, J.F. Ade, Christian Missions in Nigeria, 1841-1891: The Making of a New Élite Ibadan History Series, Longmans, 1965.

Anderson, Siwan, "Legal Origins and Female HIV," American Economic Review, June 2018, 108 (6), 1407-1439.

Angrist, J.D. and J.S. Pischke, Mostly Harmless Econometrics: An Empiricist's Companion, Princeton University Press, 2009.

Apata, ZO, "Lugard and the Creation of Provincial Administration in Northern Nigeria 1900-1918," Transafrican Journal of History, 1992, pp. 111-123.

Archibong, Belinda and Nonso Obikili, "Prison labor: The price of prisons and the lasting effects of incarceration," African Economic History Working Paper Series, 2020, (52).

Aromolaran, Adebayo, "Estimates of Mincerian Returns to Schooling in Nigeria," Oxford Development Studies, 2006, 34 (2), 265-292.

Ayandele, Emmanuel Ayankanmi, The Missionary Impact on Modern Nigeria, 1842-1914: A Political and Social Analysis Ibadan History Series, Longmans, 1966.

Bai, Ying and James Kai sing Kung, "Diffusing knowledge while spreading God's message: Protestantism and economic prosperity in China, 1840-1920," Journal of the European Economic Association, 2015, 13 (4), 669-698.

Barnes, Andrew E., "Evangelization Where It Is Not Wanted: Colonial Administrators and Missionaries in Northern Nigeria During the First Third of the Twentieth Century," Journal of Religion in Africa, 1995, 25 (4), pp. 412-441.

Bertocchi, Graziella and Arcangelo Dimico, "The long-term determinants of female HIV infection in Africa: The slave trade, polygyny, and sexual behavior," Journal of Development Economics, 2019, 140, 90-105. 
Blau, Francine D. and Lawrence M. Kahn, "Gender Differences in Pay," Journal of Economic Perspectives, Fall 2000, 14 (4), 75-99.

Bloom, David E, David Canning, Günther Fink, and Jocelyn E Finlay, "Fertility, female labor force participation, and the demographic dividend," Journal of Economic growth, 2009, 14 (2), 79-101.

Bloom, David E., David Canning, Günther Fink, and Jocelyn E. Finlay, "Fertility, female labor force participation, and the demographic dividend," Journal of Economic Growth, Jun 2009, 14 (2), $79-101$.

Bolt, Jutta and Leigh Gardner, "How Africans Shaped British Colonial Institutions: Evidence from Local Taxation," The Journal of Economic History, 2020, 80 (4), 1189-1223.

Brodeur, Abel, Marie Mabeu, and Roland Pongou, "Ancestral Norms, Legal Origins, and Female Empowerment," 2020.

Burdon, John A, "The Fulani Emirates of Northern Nigeria," The Geographical Journal, 1904, 24 (6), 636-651.

Buxton, Thomas Fowell, The African Slave Trade, and Its Remedy, J. Murray, 1840.

Cagé, Julia and Valeria Rueda, "Sex and the mission: the conflicting effects of early Christian missions on HIV in sub-Saharan Africa," Journal of Demographic Economics, 2020, 86 (3), 213-257.

Caicedo, Felipe Valencia, "The mission: Human capital transmission, economic persistence, and culture in South America," The Quarterly Journal of Economics, 2019, 134 (1), 507-556.

Calvi, Rossella, Lauren Hoehn-Velasco, and Federico G Mantovanelli, "The Protestant Legacy: Missions, Gender, and Human Capital in India," Journal of Human Resources, 2020, pp. 0919-10437R2.

Canning, D, MC Mabeu, and R Pongou, "Colonial Origins and Fertility: Can the Market Overcome History," Unpublished Manuscript, 2021.

CIA, United States Central Intelligence Agency, Nigeria, Administrative Divisions, Washington, DC: Central Intelligence Agency] [Map], 1962. Available at The Library of Congress: https://www.loc.gov/ item/94686058.

Csapo, Marg, "Religious, social and economic factors hindering the education of girls in northern Nigeria," Comparative education, 1981, 17 (3), 311-319.

Dev, Pritha, Blessing U Mberu, and Roland Pongou, "Ethnic inequality: Theory and evidence from formal education in Nigeria," Economic Development and Cultural Change, 2016, 64 (4), 603-660.

Earth, Natural, Rivers, Lake Centerlines, Made with Natural Earth. Free Vector and Raster Map Data at naturalearthdata.com, 2018.

Elkaim, Zachary, Boko Haram: The rise, success, and continued efficacy of the insurgency in Nigeria, JSTOR, 2012.

_ , "Boko Haram: The Rise, Success, and Continued Efficacy of the Insurgency in Nigeria," Technical Report, International Institute for Counter-Terrorism (ICT) 2012.

Fischer, G., F. Nachtergaele, S. Prieler, H.T. van Velthuizen, L. Verelst, and D. Wiberg, Global Agro-Ecological Zones Assessment for Agriculture (GAEZ 2008), IIASA, Laxenburg, Austria and FAO, Rome, Italy, 2008. 
Fourie, Johan and Christie Swanepoel, "When selection trumps persistence. The lasting effect of missionary education in South Africa," TSEG-The Low Countries Journal of Social and Economic History, 2015, $12(1), 1-30$.

GADM, University of California, Berkeley, Museum of Vertebrate Zoology, GADM Database of Global Administrative Areas, version 3.6, University of California, Berkeley, 2019. Available at www.gadm. org.

Gallego, Francisco A. and Robert Woodberry, "Christian Missionaries and Education in Former African Colonies: How Competition Mattered," Journal of African Economies, 2010, 19 (3), 294-329.

Galor, Oded, Unified growth theory, Princeton University Press, 2011.

- and David N Weil, "From Malthusian stagnation to modern growth," American Economic Review, 1999, 89 (2), 150-154.

_ and _, "Population, technology, and growth: From Malthusian stagnation to the demographic transition and beyond," American economic review, 2000, 90 (4), 806-828.

Gbadamosi, G. O., "The Establishment of Western Education Among Muslims in Nigeria 1896-1926," Journal of the Historical Society of Nigeria, 1967, 4 (1), 89-115.

Gershman, Boris, "Witchcraft beliefs as a cultural legacy of the Atlantic slave trade: Evidence from two continents," European Economic Review, 2020, 122, 103362.

Gething, Peter W, Thomas P Van Boeckel, David L Smith, Carlos A Guerra, Anand P Patil, Robert W Snow, and Simon I Hay, "Modelling the Global Constraints of Temperature on Transmission of Plasmodium Falciparum and P. Vivax," Parasites \& Vectors, 2011, 4 (1), 92.

Giuliano, Paola and Nathan Nunn, "Ancestral characteristics of modern populations," Economic History of Developing Regions, 2018, 33 (1), 1-17.

Goldewijk, Kees Klein, Arthur Beusen, Gerard Van Drecht, and Martine De Vos, "The HYDE 3.1 Spatially Explicit Database of Human-Induced Global Land-Use Change Over the Past 12,000 Years," Global Ecology and Biogeography, 2011, 20 (1), 73-86.

Harris, I., P.D. Jones, T.J. Osborn, and D.H. Lister, "Updated High-Resolution Grids of Monthly Climatic Observations - the CRU TS3.10 Dataset," International Journal of Climatology, 2014, 34 (3), 623-642.

Hastings, David A and Paula K Dunbar, "Global Land One-kilometer Base Elevation (GLOBE)," 1993.

Huillery, Elise, "History matters: The long-term impact of colonial public investments in French West Africa," American Economic Journal: Applied Economics, 2009, pp. 176-215.

Jedwab, Remi and Alexander Moradi, "The Permanent Effects of Transportation Revolutions in Poor Countries: Evidence from Africa," Review of economics and statistics, 2016, 98 (2), 268-284.

_, Felix Meier zu Selhausen, and Alexander Moradi, "The economics of missionary expansion: evidence from Africa and implications for development," 2018.

_ , Felix Meier zu Selhausen, and Alexander Moradi, "The Economics of Missionary Expansion: Evidence from Africa and Implications for Development," CSAE Working Paper Series 2018-07, Centre for the Study of African Economies, University of Oxford 2018. 
Kleibergen, Frank and Richard Paap, "Generalized reduced rank tests using the singular value decomposition," Journal of Econometrics, July 2006, 133 (1), 97-126.

Last, Murray, The Sokoto Caliphate, London: Longmans, 1967.

Mabeu, MC and R Pongou, "The Interplay between Colonial History and Postcolonial Institutions: Evidence from Cameroon," Unpublished Manuscript, 2021.

Michalopoulos, Stelios and Elias Papaioannou, "National Institutions and Subnational Development in Africa," The Quarterly Journal of Economics, 2014, 129 (1), 151-213.

_ and _, "Historical Legacies and African Development," Working Paper 25278, National Bureau of Economic Research November 2018.

_ and _, "Historical legacies and African development," Journal of Economic Literature, 2020, 58 (1), $53-128$.

Murdock, G.P., Africa: Its Peoples and Their Cultural History: Maps, McGraw-Hill, 1959.

_ , Ethnographic Atlas, University of Pittsburgh Press, 1967.

NBS and ICF International, Nigeria Demographic and Health Survey [Data File], Calverton, Maryland: ICF International: Nigeria Bureau of Statistics and ICF International, 2018. Available at https:// dhsprogram.com/data/available-datasets.cfm.

Nunn, Nathan, "The long-term effects of Africa's slave trades," The Quarterly Journal of Economics, 2008, 123 (1), 139-176.

_ , "Religious Conversion in Colonial Africa," American Economic Review, 2010, 100 (2), 147-52.

_ , "Gender and Missionary Influence in Colonial Africa," in Emmanuel Akyeampong, Robert H. Bates, Nathan Nunn, and James Robinson, eds., African Development in Historical Perspective, Cambridge: Cambridge University Press, May 2014.

_ , "The historical roots of economic development," Science, 2020, 367 (6485).

- and Leonard Wantchekon, "The slave trade and the origins of mistrust in Africa," American Economic Review, 2011, 101 (7), 3221-52.

Nwabara, Samuel, "The Fulani conquest and rule of the Hausa Kingdom of Northern Nigeria (1804-1900)," Journal des Africanistes, 1963, 33 (2), 231-242.

Obikili, Nonso, "The Impact of the Slave Trade on Literacy in West Africa: Evidence from the Colonial Era," Journal of African Economies, 09 2015, 25 (1), 1-27.

Office, Great Britain Colonial, Annual Reports on the Colonies: Northern Nigeria 1902 Colonial Reports-Annual, H.M. Stationery Office, 1903. Available at https://libsysdigi.library.illinois . edu/ilharvest/Africana/Books2011-05/3064634.

-, Annual Reports on the Colonies: Northern Nigeria 1907 Colonial Reports-Annual, H.M. Stationery Office, 1908. Available at https://libsysdigi.library.illinois.edu/ilharvest/Africana/ Books2011-05/3064634.

-, Annual Reports on the Colonies: Nigeria 1914 Colonial Reports-Annual, H.M. Stationery Office, 1914. Available at https://libsysdigi.library.illinois.edu/ilharvest/Africana/Books2011-05/ 3064634. 
Okoye, Dozie, "Things fall apart? missions, institutions, and interpersonal trust," Journal of Development Economics, 2021, 148, 102568.

_ and Roland Pongou, "Historical Missionary Activity, Schooling, and the Reversal of Fortunes: Evidence from Nigeria," Schooling, and the Reversal of Fortunes: Evidence from Nigeria (August 20, 2014), 2014 .

_ and _, "Sea Changes: The Transatlantic Slave Trade and Missionary Activity in Africa," Unpublished manuscript. Retrieved December, 2017, 6, 2017.

_, _, and Tite Yokossi, "New technology, better economy? The heterogeneous impact of colonial railroads in Nigeria," Journal of Development Economics, 2019, 140, 320-354.

_ , _ , and _ , "New Technology, Better Economy? The Heterogeneous Impact of Colonial Railroads in Nigeria," Journal of Development Economics, 2019, 140 (C), 320-354.

Oostendorp, Remco H., "Globalization and the Gender Wage Gap," The World Bank Economic Review, 2009, 23 (1), 141-161.

Preston, Sarah, "The Colonial Blue Books: A Major Resource in the Royal Commonwealth Society Library," Reproduced from the Bulletin of the Friends of Cambridge University Library, 2006, 26.

Prothero, R Mansell, "The population census of Northern Nigeria 1952: Problems and results," Population Studies, 1956, 10 (2), 166-183.

Roome, William R.M., Ethnographic Survey of Africa Showing the Tribes and Languages: Also the Stations of Missionary Societies, Edward Stanford Ltd, 1925.

Rutstein, Shea Oscar and Kiersten Johnson, The DHS Wealth Index, Vol. DHS Comparative Reports No. 6, Calverton, Maryland: ORC Macro, 2004.

Sundkler, B. and C. Steed, A History of the Church in Africa: Studia Missionalia Upsaliensia, Cambridge University Press, 2000.

Tasie, G.O.M., Christian Missionary Enterprise In the Niger Delta 1864-1918 Studies on Religion in Africa, Brill, 1978.

The World Bank, "World Development Indicators. Washington, D.C.," 2016.

Thurston, Alexander, Boko Haram: the history of an African jihadist movement, Vol. 65, Princeton University Press, 2017.

— , Boko Haram: The History of an African Jihadist Movement, Princeton, NJ: Princeton University Press, 2018.

Tibenderana, Peter Kazenga, "The emirs and the spread of Western education in Northern Nigeria, 1910-1946," The Journal of African History, 1983, 24 (4), 517-534.

_- "The Emirs and the Spread of Western Education in Northern Nigeria, 1910-1946," The Journal of African History, 1983, 24 (4), 517-534.

Ubah, C.N., "Christian Missionary Penetration of the Nigerian Emirates: The Village School Approach," Transafrican Journal of History, 1988, 17, 108-122.

Waldinger, Maria, "The long-run effects of missionary orders in Mexico," Journal of Development Economics, 2017, 127, 355-378. 
Wantchekon, Leonard, Marko Klašnja, and Natalija Novta, "Education and human capital externalities: evidence from colonial Benin," The Quarterly Journal of Economics, 2015, 130 (2), 703-757.

Woodberry, Robert D, "The missionary roots of liberal democracy," American political science review, 2012, $106(2), 244-274$. 


\section{Appendices}

\section{A Other Tables and Figures}

Figure A1: Map of Colonial Nigeria

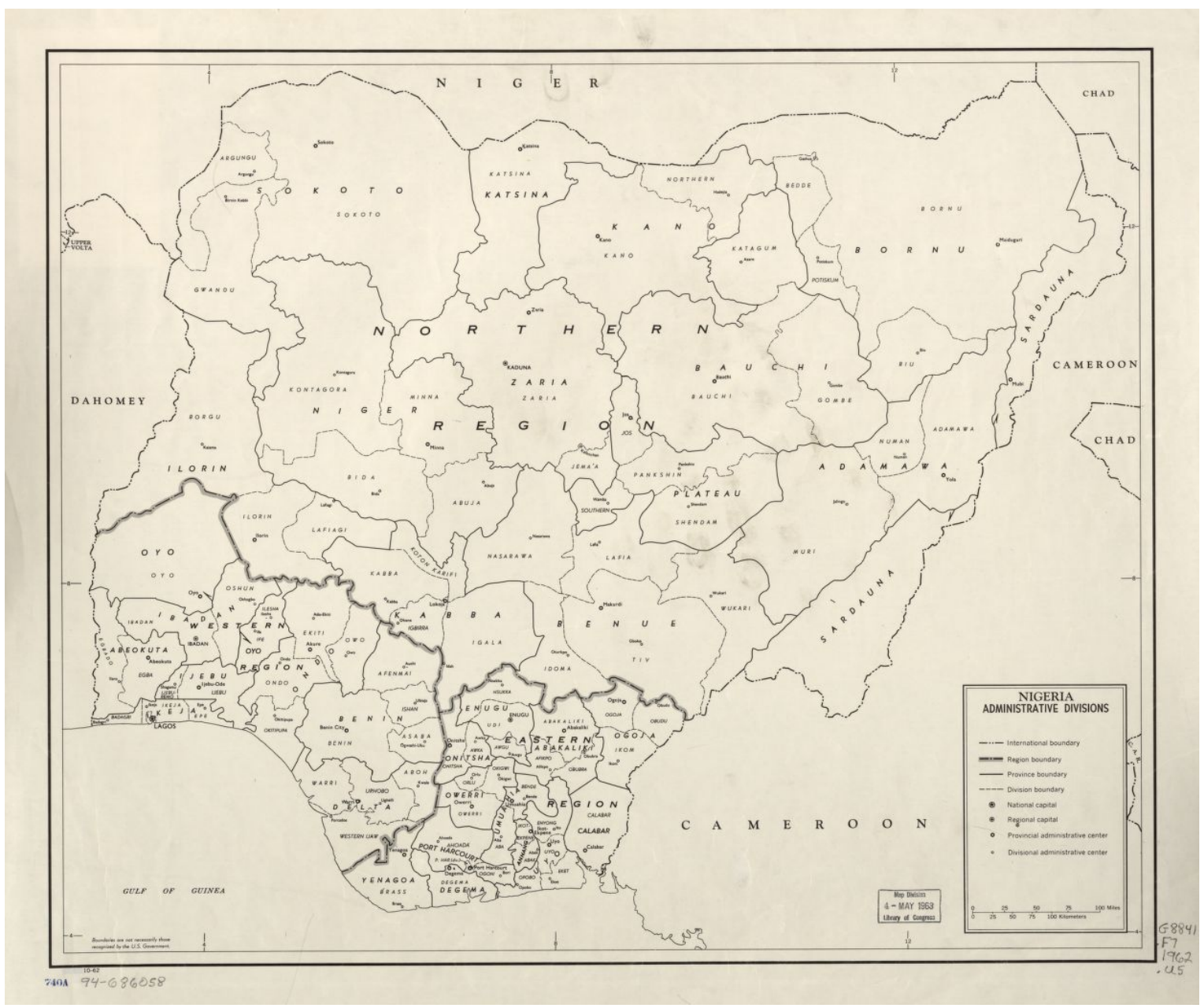

Source: The Library of Congress (CIA, 1962). 
Figure A2: Discontinuity of Mission Presence and Schooling Within and Outside Restricted Areas (Linear)

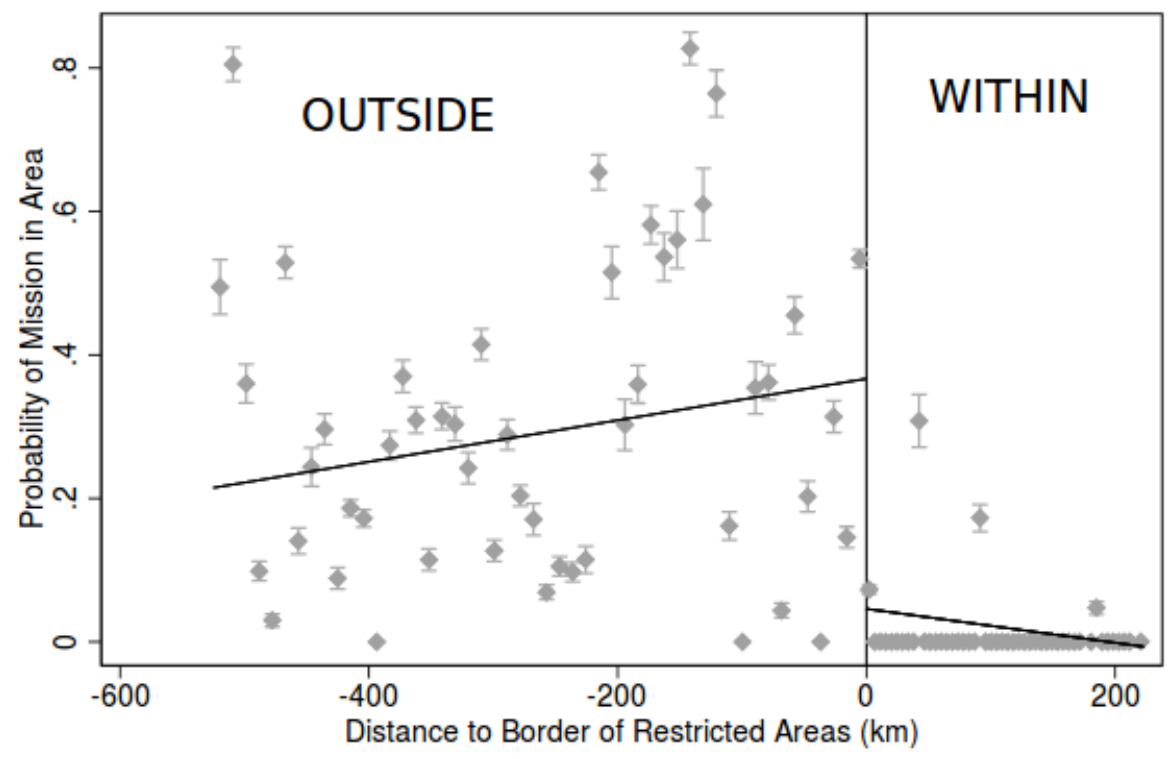

- Sample average within bin $\quad$ Polynomial fit of order 1

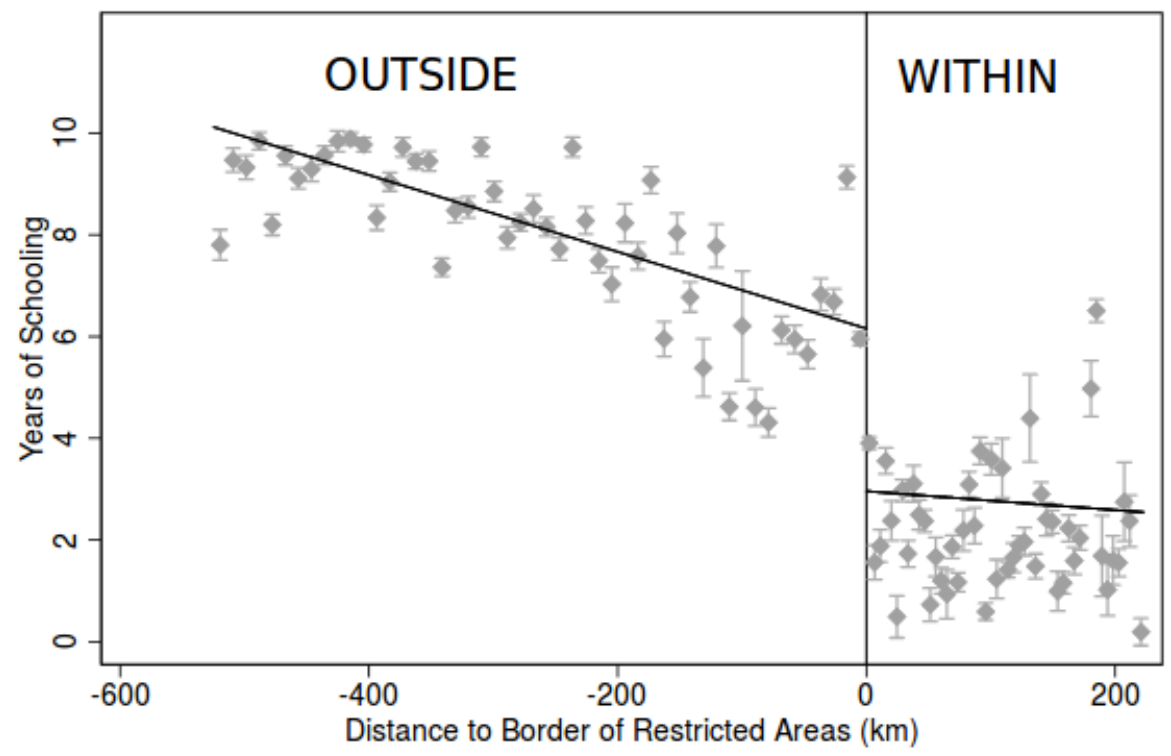

Sample average within bin Polynomial fit of order 1

Note: Points show binned means using 50 bins. Standard errors clustered at the local government area level, and bars show $95 \%$ confidence intervals. Regression line is estimated using a linear regression function. Negative distance indicates areas outside the restricted areas and positive distance indicates restricted areas. 
Figure A3: Placebo: Discontinuity of Missions with Artificial Border 50km South and North of Restricted Areas
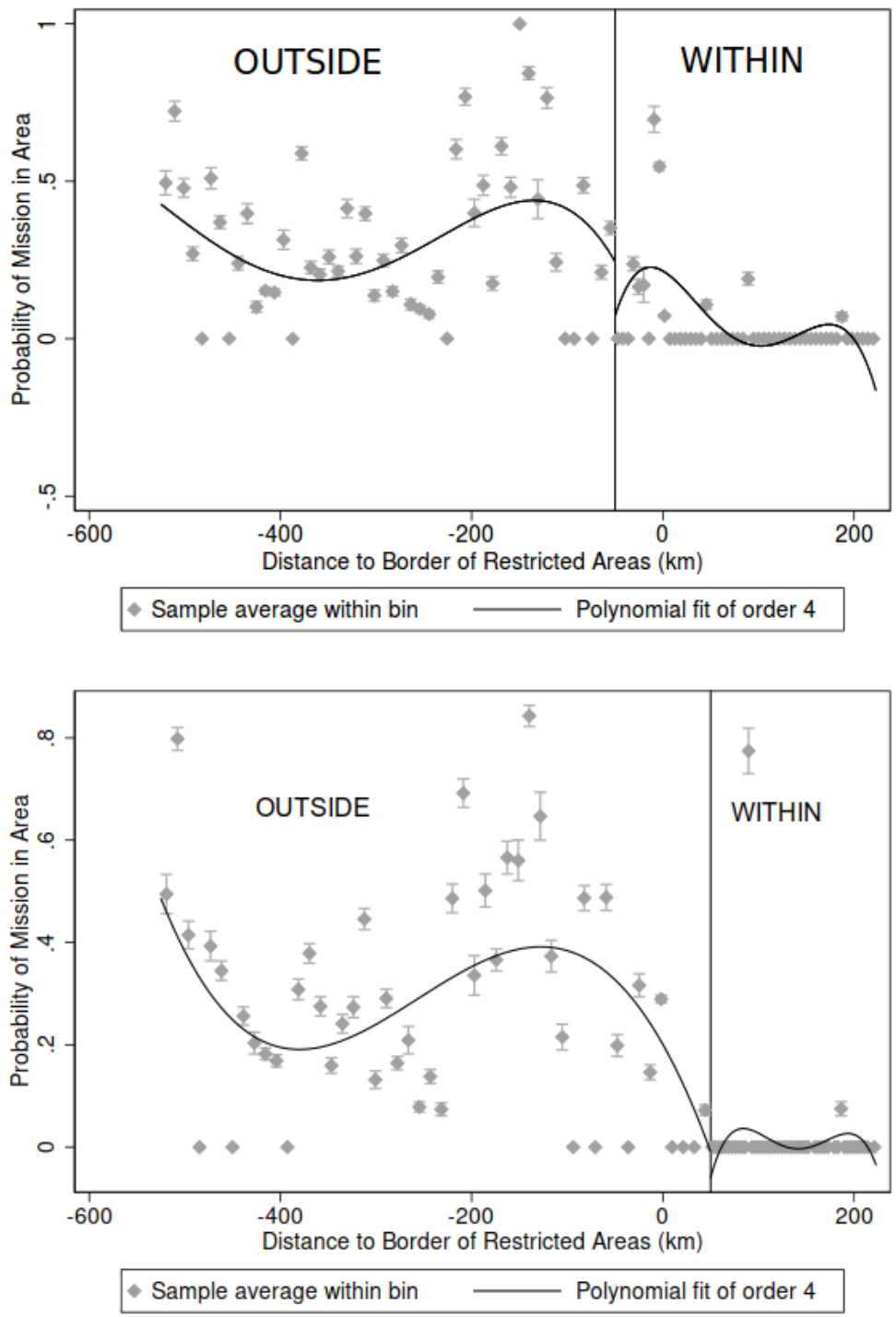

Note: Figures show no discontinuity for alternate borders within Northern Nigeria, $50 \mathrm{~km}$ south and north of restricted areas. Points show binned means using 50 bins. Standard errors clustered at the local government area level, and bars show $95 \%$ confidence intervals. Regression line is estimated using a linear regression function. Negative distance indicates areas outside the restricted areas and positive distance indicates restricted areas. 
Figure A4: Differences in Ideal Number of Children Within and Outside Restricted Areas

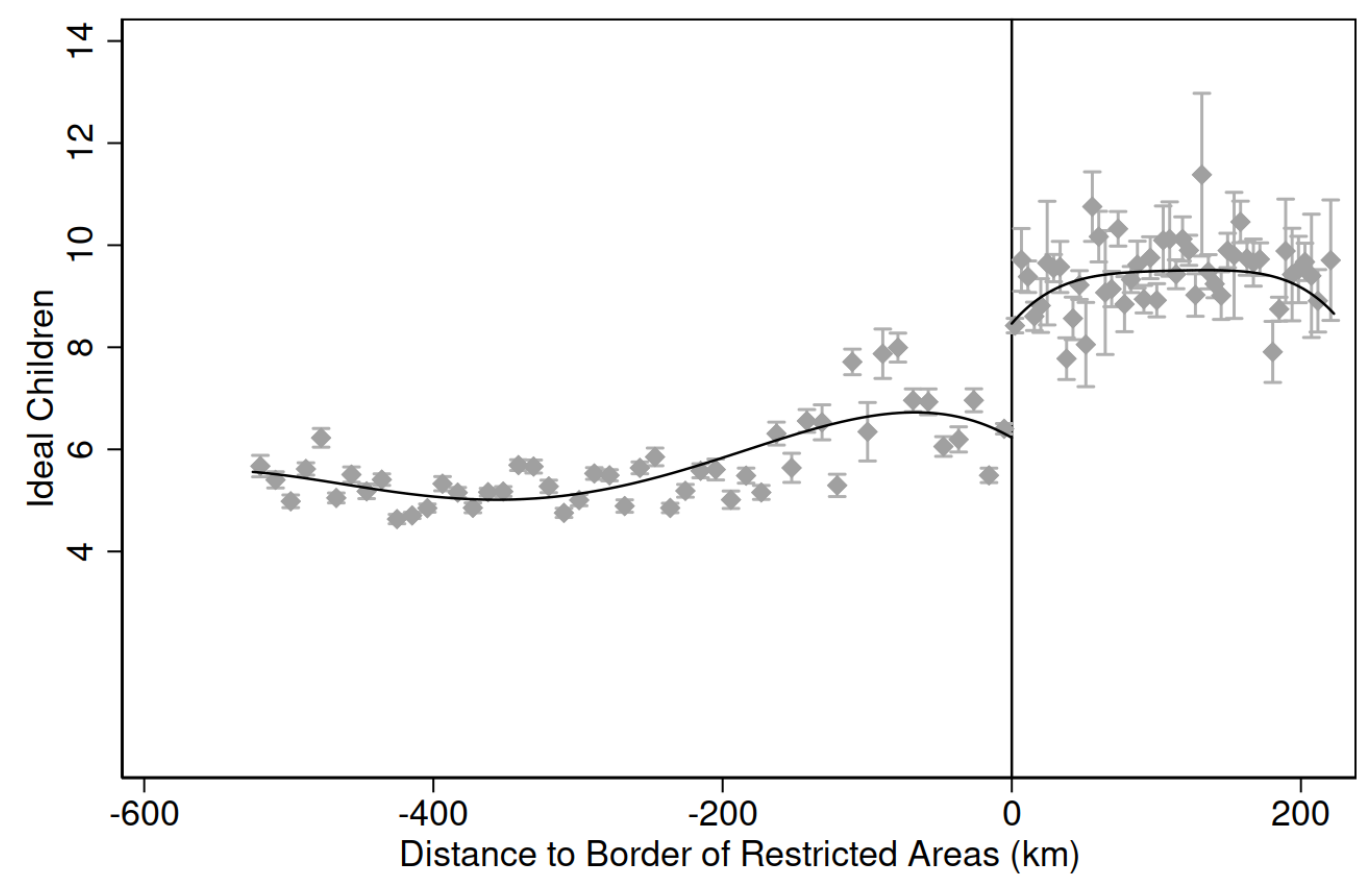

- Sample average within bin $\quad$ Polynomial fit of order 4

Note: Points show binned means using 50 bins. Standard errors clustered at the local government area level, and bars show $95 \%$ confidence intervals. Regression line is estimated using fourth-order polynomials of distance to restricted areas. Negative distance indicates areas outside the restricted areas and positive distance indicates restricted areas. 
Figure A5: Differences in Total Number of Children to each Adult Female Within and Outside Restricted Areas

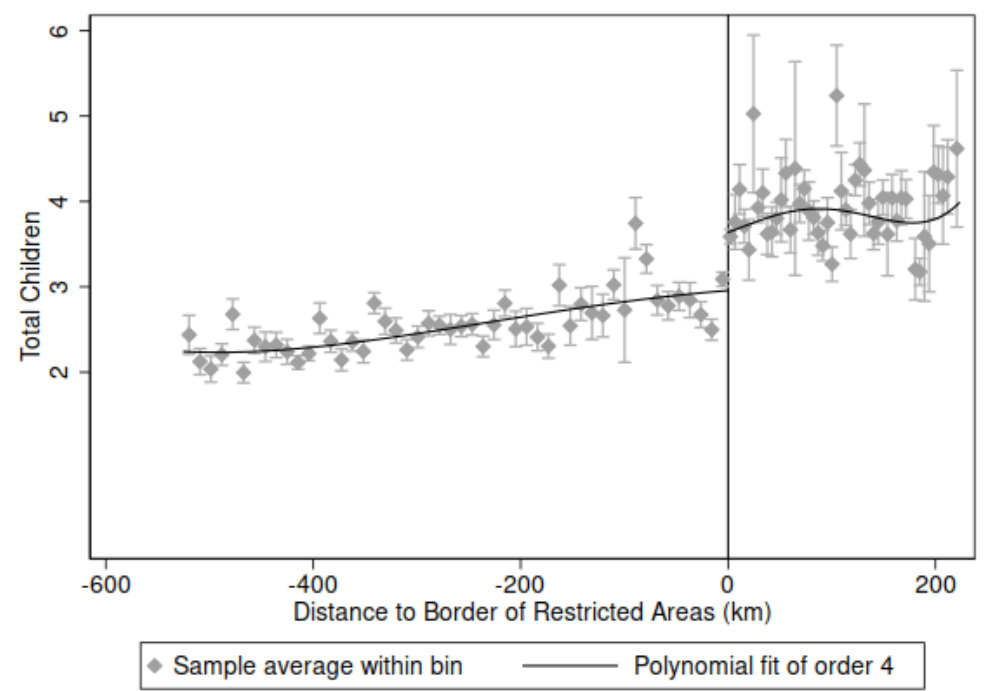

Note: Points show binned means using 50 bins. Standard errors clustered at the local government area level, and bars show $95 \%$ confidence intervals. Regression line is estimated using fourth-order polynomials of distance to restricted areas. Negative distance indicates areas outside the restricted areas and positive distance indicates restricted areas.

Figure A6: Differences in Number of Living Children per Adult Female Within and Outside Restricted Areas

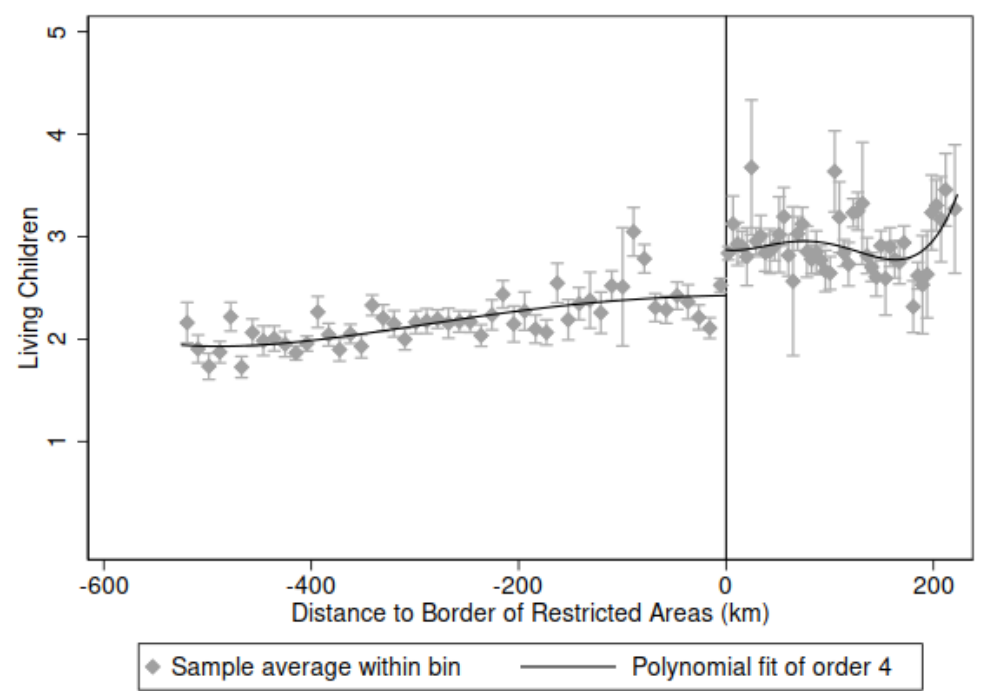

Note: Points show binned means using 50 bins. Standard errors clustered at the local government area level, and bars show $95 \%$ confidence intervals. Regression line is estimated using fourth-order polynomials of distance to restricted areas. Negative distance indicates areas outside the restricted areas and positive distance indicates restricted areas. 


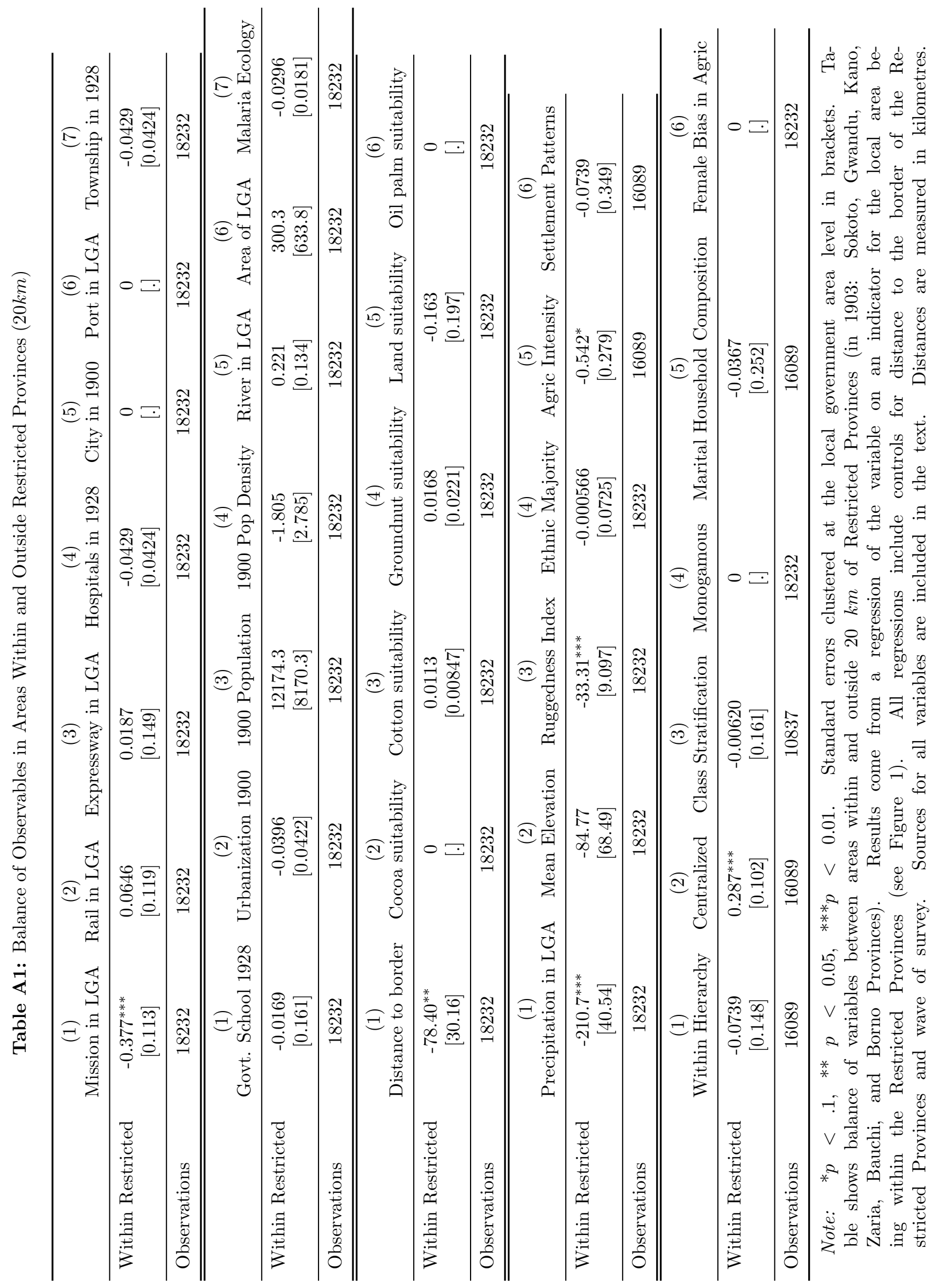




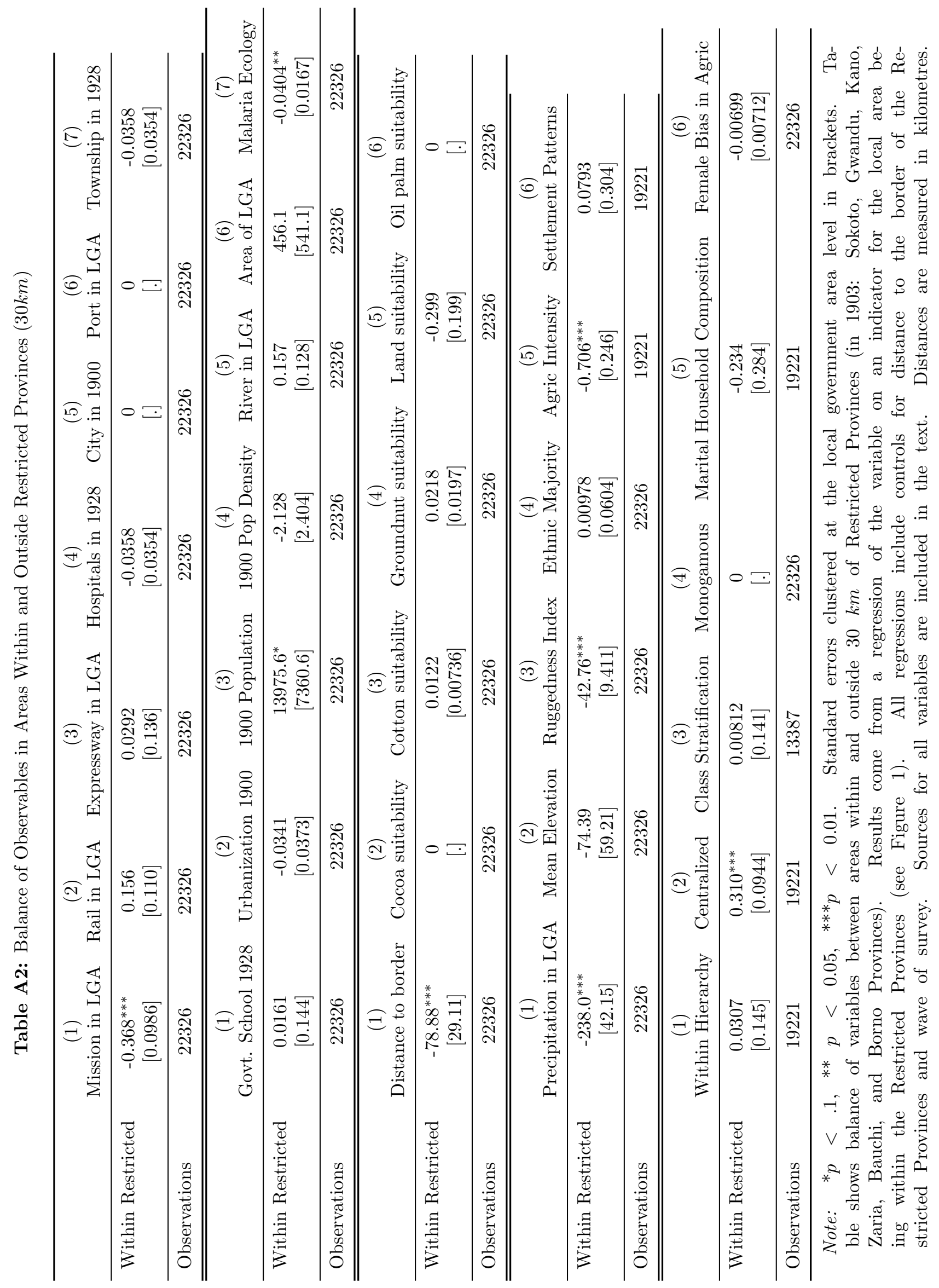


Table A3: Effects of Missions on Education Related Outcomes

\begin{tabular}{|c|c|c|c|}
\hline & $\begin{array}{c}(1) \\
\text { Literate }\end{array}$ & $\begin{array}{c}(2) \\
\text { Primary Completed }\end{array}$ & $\begin{array}{c}(3) \\
\text { Secondary Completed }\end{array}$ \\
\hline Within $20 \mathrm{~km}$ & $\begin{array}{l}0.197^{* * *} \\
{[0.0319]}\end{array}$ & $\begin{array}{l}0.213^{* * *} \\
{[0.0336]}\end{array}$ & $\begin{array}{l}0.147^{* * *} \\
{[0.0299]}\end{array}$ \\
\hline Between 20 and $40 \mathrm{~km}$ & $\begin{array}{l}0.128^{* * *} \\
{[0.0327]}\end{array}$ & $\begin{array}{l}0.134^{* * *} \\
{[0.0324]}\end{array}$ & $\begin{array}{c}0.0825^{* *} \\
{[0.0320]}\end{array}$ \\
\hline Between 40 and $60 \mathrm{~km}$ & $\begin{array}{l}0.0765^{* *} \\
{[0.0372]}\end{array}$ & $\begin{array}{c}0.0904^{* *} \\
{[0.0373]}\end{array}$ & $\begin{array}{c}0.0445 \\
{[0.0355]}\end{array}$ \\
\hline Between 60 and $80 \mathrm{~km}$ & $\begin{array}{c}0.0374 \\
{[0.0371]}\end{array}$ & $\begin{array}{l}0.0781^{* *} \\
{[0.0361]}\end{array}$ & $\begin{array}{c}0.0125 \\
{[0.0325]}\end{array}$ \\
\hline $\begin{array}{l}\text { Mean Outcome } \\
\text { North Fixed Effect } \\
\text { Geographic Controls } \\
\text { Colonial Investments } \\
\text { Population Conditions } \\
\text { Ethnic Heritage } \\
\text { Adjusted R } \\
\text { Number of LGA's } \\
\text { Observations }\end{array}$ & $\begin{array}{c}0.559 \\
\text { Yes } \\
\text { Yes } \\
\text { Yes } \\
\text { Yes } \\
\text { Yes } \\
0.359 \\
600 \\
100099\end{array}$ & $\begin{array}{c}0.668 \\
\text { Yes } \\
\text { Yes } \\
\text { Yes } \\
\text { Yes } \\
\text { Yes } \\
0.413 \\
600 \\
100781\end{array}$ & $\begin{array}{c}0.470 \\
\text { Yes } \\
\text { Yes } \\
\text { Yes } \\
\text { Yes } \\
\text { Yes } \\
0.284 \\
600 \\
100781\end{array}$ \\
\hline
\end{tabular}

Note: ${ }^{*} p<.1,{ }^{* *} p<0.05,{ }^{* * *} p<0.01$. Standard errors clustered at the local government area levels in brackets. Table shows estimates of the effects of historical missionary activity on education related outcomes in Nigeria, using data from the 1990, 2003, 2008, and 2013, Demographic and Health Surveys. The excluded category are local areas beyond $80 \mathrm{~km}$ of 1928 primary mission stations. North fixed effect refers to the states of historical Northern Nigeria. Geographic controls include controls for a number of geographic and agricultural characteristics and include distance to coast, presence of a major river, total area of the LGA, malaria ecology of the LGA, distance to the nearest border, suitability for primary export crops in the colonial era (cocoa, cotton, groundnuts, and oil palm), mean precipitation, elevation, and ruggedness. Colonial investments refer to controls for major colonial-era investments and include presence of the railway line, presence of a major motorway, presence of a hospital, city presence in 1900 , presence of a major seaport, township presence in 1928, and presence of a government school in 1928 . Population conditions refer to urbanization rate of local area in 1900, total population of local area in 1900, and 1900 population density of local area. Ethnic heritage controls include an indicator for whether there is an ethnic majority in the local area, and measures for the intensity of agriculture, settlement patterns, political hierarchy, centralization, class stratification, marital living composition, female bias in agriculture, and bride price payments, for the majority historical ethnic group in the local area. All regressions include indicators for wave of survey, and variables are constructed as described in the text. 
Table A4: Fuzzy RD: Effects of Missions on Fertility in Areas Within 20km of Restricted Provinces

Panel A: Second-Stage Estimates

\begin{tabular}{lccc}
\hline & $(1)$ & $(2)$ & $(3)$ \\
& Total Children & Living Children & Ideal Children \\
\hline Mission in LGA & $-1.045^{*}$ & $-0.863^{*}$ & $-2.006^{*}$ \\
& {$[0.582]$} & {$[0.460]$} & {$[1.120]$} \\
\hline Mean Outcome & 3.316 & 2.655 & 7.423 \\
Observations & 10837 & 10837 & 9145 \\
Number of LGA's & 57 & 57 & 57 \\
Centered R-sq. & 0.02 & 0.01 & 0.06 \\
Kleibergen-Paap UnderId & 7.76 & 7.76 & 7.60 \\
Kleibergen-Paap Wald F & 7.65 & 7.65 & 7.48 \\
& & & \\
\hline
\end{tabular}

Panel B: First Stage Estimates, Dependent Variable in Mission in Local Area

\begin{tabular}{lccc}
\hline & $(1)$ & $(2)$ & $(3)$ \\
& Mission in LGA & Mission in LGA & Mission in LGA \\
\hline Within Restricted Provinces & $-0.345^{* * *}$ & $-0.345^{* * *}$ & $-0.353^{* * *}$ \\
& {$[0.125]$} & {$[0.125]$} & {$[0.129]$} \\
Observations & 10837 & 10837 & 9145 \\
\hline Geographic Controls & Yes & Yes & Yes \\
Colonial Investments & Yes & Yes & Yes \\
Population Conditions & Yes & Yes & Yes \\
Ethnic Heritage & Yes & Yes & Yes \\
\hline
\end{tabular}

Note: ${ }^{*} p<.1,{ }^{* *} p<0.05,{ }^{* * *} p<0.01$. Standard errors clustered at the local government area levels in brackets. Table shows instrumental variable estimates of the effects of historical missionary activity on fertility in Nigeria, using data from the 1990, 2003, 2008, and 2013, Demographic and Health Surveys. The sample is restricted to local areas within $20 \mathrm{~km}$ of the Restricted Provinces (in 1903: Sokoto, Gwandu, Kano, Zaria, Bauchi, and Borno Provinces), and the instrument is an indicator for being within the Provinces, and the instrument is an indicator being within the Provinces. The Table also shows test statistics from the Kleibergen and Paap (2006) LM-test of under-identification (KleibergenPaap UnderId) and the Kleibergen and Paap (2006) F-test of weak identification (Kleibergen-Paap Wald F). Regressions control for variables that vary between local areas. Geographic controls include controls for a number of geographic and agricultural characteristics: distance to border of the Restricted Provinces, presence of a major river, total area of the LGA, malaria ecology of the LGA, distance to the nearest border, suitability for primary export crops in the colonial era in the region (cotton, groundnuts), mean precipitation, elevation, and ruggedness. Colonial investments refer to controls for major colonial-era investments in the region and include presence of the railway line, presence of a major motorway, presence of a hospital, township presence in 1928, and presence of a government school in 1928. Population conditions refer to urbanization rate of local area in 1900, total population of local area in 1900, and 1900 population density of local area. Ethnic heritage controls include an indicator for whether there is an ethnic majority in the local area, and measures for the intensity of agriculture, settlement patterns, political hierarchy, centralization, class stratification, and marital living composition for the majority historical ethnic group in the local area. All regressions include indicators for wave of survey, and variables are constructed as described in the text. 
Table A5: Colonial Investments in Areas Within and Outside Restricted Provinces

Panel A: All Areas

\begin{tabular}{lccccccc}
\hline & $(1)$ & $(2)$ & $(3)$ & $(4)$ & $(5)$ & $(6)$ & $(7)$ \\
& Missions & Rail & Motorway $(1950 \mathrm{~s})$ & Hospitals & Port & $\begin{array}{c}(6) \\
\text { Township }\end{array}$ & Govt. Schools \\
\hline Within Restricted Provinces & $-0.433^{* * *}$ & $0.172^{*}$ & 0.151 & 0.0274 & 0.00770 & -0.00440 & 0.122 \\
& {$[0.105]$} & {$[0.0903]$} & {$[0.113]$} & {$[0.0198]$} & {$[0.0105]$} & {$[0.0306]$} & {$[0.105]$} \\
\hline Mean Outcome & 0.720 & 0.193 & 0.347 & 0.032 & 0.015 & 0.044 & 0.187 \\
North Fixed Effect & Yes & Yes & Yes & Yes & Yes & Yes & Yes \\
Geographic Controls & Yes & Yes & Yes & Yes & Yes & Yes & Yes \\
Population Conditions & Yes & Yes & Yes & Yes & Yes & Yes & Yes \\
Ethnic Heritage & Yes & Yes & Yes & Yes & Yes & Yes & Yes \\
Adjusted R & 0.618 & 0.138 & 0.0967 & 0.0743 & 0.151 & 0.0703 & 0.0596 \\
Number of LGA's & 600 & 600 & 600 & 600 & 600 & 600 & 600 \\
Observations & 100781 & 100781 & 100781 & 100781 & 100781 & 100781 & 100781 \\
\hline
\end{tabular}

Panel B: Areas in Northern Nigeria

\begin{tabular}{lccccccc}
\hline & $(1)$ & $(2)$ & $(3)$ & $(4)$ & $(5)$ & $(6)$ & $(7)$ \\
& Missions & Rail & Motorway $(1950 \mathrm{~s})$ & Hospitals & Port & $\begin{array}{c}\text { Township } \\
\text { Govt. Schools }\end{array}$ \\
\hline Within Restricted Provinces & $-0.363^{* * *}$ & 0.0318 & 0.0133 & -0.0232 & 0 & -0.0503 & 0.0913 \\
& {$[0.129]$} & {$[0.0904]$} & {$[0.137]$} & {$[0.0228]$} & {$[]$.} & {$[0.0354]$} & {$[0.114]$} \\
\hline Mean Outcome & 0.500 & 0.217 & 0.336 & 0.020 & 0.000 & 0.033 & 0.240 \\
North Fixed Effect & No & No & No & No & No & No & No \\
Geographic Controls & Yes & Yes & Yes & Yes & Yes & Yes & Yes \\
Population Conditions & Yes & Yes & Yes & Yes & Yes & Yes & Yes \\
Ethnic Heritage & Yes & Yes & Yes & Yes & Yes & Yes & Yes \\
Adjusted R & 0.592 & 0.216 & 0.161 & 0.119 &. & 0.0976 & 0.0781 \\
Number of LGA's & 296 & 296 & 296 & 296 & 296 & 296 & 296 \\
Observations & 52375 & 52375 & 52375 & 52375 & 52375 & 52375 & 52375 \\
\hline
\end{tabular}

Note: ${ }^{*} p<.1,{ }^{* *} p<0.05,{ }^{* * *} p<0.01$. Standard errors clustered at the local government area levels in brackets. Table shows estimates of the relationship between living within the restricted provinces and local development today, accounting for missionary activities. Regression using household wealth measures control for household size. North fixed effect refers to the states of historical Northern Nigeria. Geographic controls include controls for a number of geographic and agricultural characteristics and include distance to coast, presence of a major river, total area of the LGA, malaria ecology of the LGA, distance to the nearest border, suitability for primary export crops in the colonial era (cocoa, cotton, groundnuts, and oil palm), mean precipitation, elevation, and ruggedness. Colonial investments refer to controls for major colonial-era investments and include presence of the railway line, presence of a major motorway, presence of a hospital, city presence in 1900, presence of a major seaport, township presence in 1928, and presence of a government school in 1928. Population conditions refer to total population of local area in 1900. Ethnic heritage controls include an indicator for whether there is an ethnic majority in the local area, and measures for the intensity of agriculture, settlement patterns, political hierarchy, class stratification, marital living composition, female bias in agriculture, and bride price payments, for the majority historical ethnic group in the local area. All regressions include indicators for wave of survey, and variables are constructed as described in the text. 


\section{B A Model of Schooling and Schooling Infrastructure}

Let $i$ be an individual who has to decide on the amount of education they would like to acquire. The benefits of education such as higher incomes, better living standards, prestige, and knowledge, increase with the level of education. Education is also costly to acquire, and the cost is lower with a higher supply of educational infrastructure. By education infrastructure, we mean physical infrastructure, as well as the availability of teachers and teaching materials used in schools.

Individual $i$ 's utility function is: ${ }^{32}$

$$
u(e)=\alpha b(e)-\frac{c(e)}{I}
$$

Where $e$ is the amount of education, $b(e)$ the benefit of acquiring $e$ units of education, and $c(e)$ the cost of $e$ units of education. The parameter $\alpha$ denotes the degree of sex discrimination in the labour market, and we assume $\alpha=1$ if $i$ is male, and $0<\alpha<1$ if $i$ is female. We include this parameter to recognize substantial labour market discrimination against females in Nigeria, as documented in Aromolaran (2006). The quantity of available educational infrastructure is denoted by $I$. For simplicity, $e$ and $I$ are assumed to be positive real numbers. Also, $b$ is assumed to be twice-continuously differentiable, increasing, and strictly concave, and $c$ is assumed to be twice-continuously differentiable, increasing, and strictly convex.

Individual $i$ maximizes their utility function by choosing the optimal amount of education $e^{*}$ given $I>0$. From the first order condition of the consumer problem, we know that at the optimal level of education, marginal benefits must equal marginal costs:

$$
g\left(e^{*}, I\right)=0, \quad \text { where } \quad g(e, I)=\alpha b^{\prime}(e)-\frac{c^{\prime}(e)}{I} .
$$

The first implication of the model is given by proposition 1 below:

Proposition 1. The optimal amount of education, $e^{*}$, is increasing in the amount of education infrastructure, $I$.

To see why proposition 1 is true, note that the function $g$ is decreasing in education because the marginal benefit, $b$, is decreasing in education and the marginal cost, $c$ is increasing. Increasing the quantity of education infrastructure lowers the marginal cost, which means that $g(e, I)>0$. By the assumptions on $b()$ and $c()$, the intermediate value theorem implies that the quantity of education must increase to equate marginal benefits and costs as in equation (2). Our primary argument in the rest of the paper is that the sustained differences in schooling across areas is driven by the increase in education infrastructure brought by missionaries, all else the same.

Next, we explore other results which we use to test the implications of the model. The model also implies that in the presence of sex discrimination against females, $0<\alpha<1$, the marginal impact of missionary activity driven by increases in infrastructure would be greater for females. This is summarized in proposition 2 below:

Proposition 2. The marginal effect of increasing education infrastructure on schooling attainment is decreasing in $\alpha$. Thus, as long as there is some wage discrimination against females compared to males, $0<\alpha<1$, the marginal impact of missionary education on schooling would be larger for females.

\footnotetext{
${ }^{32}$ Note that an alternative way to model educational choice would be to assume that $i$ derives utility from consumption, but consumption depends on income (first constraint), and income depends on education level (second constraint incorporating a parameter of income discrimination against females). Also, education is costly, but the cost is lower with higher educational infrastructure (budget constraint). Solving this problem will be similar to the one we solve.
} 
To show the proposition above formally, we apply the implicit function theorem to equation (2), and take derivatives to find that:

$$
\frac{d e^{*}}{d I}=-\frac{\frac{c^{\prime}\left(e^{*}\right)}{I^{2}}}{\alpha b^{\prime \prime}\left(e^{*}\right)-\frac{c^{\prime \prime}\left(e^{*}\right)}{I}} .
$$

Given that $c^{\prime}>0, c^{\prime \prime}>0, b^{\prime \prime}<0$, equation (3) implies that the impact of increases in infrastructure is higher for females, because the denominator in (3) is smaller when $0<\alpha<1$. The intuition for this result is as follows: wage discrimination implies that females have higher marginal benefits to education because of lower levels of schooling (for sociocultural reasons males are sent to school first Ayandele (1966)). With an increase in infrastructure, the marginal increase in educational attainment would be more responsive for females compared to men who already have higher levels of education and lower marginal benefits. In the extreme case, think of a community where all males must go to school first before females because of infrastructural constraints. The responsiveness of female education to expanded infrastructure would be greater than that of males, because more males are already in school.

Lastly, the model implies that the marginal effect of educational infrastructure on the optimal amount of education decreases with the supply of educational infrastructure. We want to show that $\frac{d^{2} e^{*}}{d I^{2}}<0$. Differentiating equation (3) yields:

$$
\frac{d^{2} e^{*}}{d I^{2}}=-\frac{-\alpha b^{\prime \prime}\left(e^{*}\right) \frac{2 c^{\prime}\left(e^{*}\right)}{I^{3}}+\frac{c^{\prime}\left(e^{*}\right) c^{\prime \prime}\left(e^{*}\right)}{I^{4}}}{\left(\alpha b^{\prime \prime}\left(e^{*}\right)-\frac{c^{\prime \prime}\left(e^{*}\right)}{I}\right)^{2}}
$$

Given that $c^{\prime}>0, c^{\prime \prime}>0$, and $b^{\prime \prime}<0$, equation (4) implies that $\frac{d^{2} e^{*}}{d I^{2}}<0$. The result implies that within groups with less historical missionary activity, and less supply of educational infrastructure today, the marginal effect of missionary activities on educational attainment would be larger. This is an immediate implication of decreasing marginal benefit to education for an individual, so that further reductions in costs would lead to smaller increases in educational attainment. The third result is summarized below:

Proposition 3. The marginal effect of increasing education infrastructure on schooling attainment is decreasing in the amount of infrastructure, $I$.

Importantly, the result means that the marginal effect of missionary activity on schooling would be greater for groups with less average historical exposure to missionaries. This is a result that illustrates the contrast between our model and models where missionaries simply increased tastes for education (benefits). In such a model, the impact of missionary activity would be greater in areas with more missionary activity where one would expect the change in tastes to be greater. We test this last prediction by splitting the sample into Christians (high missionary activity) and Muslims. 